\title{
Development of a Representative EV Urban Driving Cycle Based on a k-Means and SVM Hybrid Clustering Algorithm
}

\author{
Xuan Zhao (D), Qiang Yu, Jian Ma, Yan Wu, Man Yu, and Yiming Ye \\ School of Automobile, Chang'an University, Xian, China \\ Correspondence should be addressed to Xuan Zhao; zhaoxuan@chd.edu.cn
}

Received 21 May 2018; Revised 1 September 2018; Accepted 17 September 2018; Published 5 November 2018

Academic Editor: Constantinos Antoniou

Copyright (C) 2018 Xuan Zhao et al. This is an open access article distributed under the Creative Commons Attribution License, which permits unrestricted use, distribution, and reproduction in any medium, provided the original work is properly cited.

\begin{abstract}
This paper proposes a scientific and systematic methodology for the development of a representative electric vehicle (EV) urban driving cycle. The methodology mainly includes three tasks: test route selection and data collection, data processing, and driving cycle construction. A test route is designed according to the overall topological structure of the urban roads and traffic flow survey results. The driving pattern data are collected using a hybrid method of on-board measurement method and chase car method. Principal component analysis (PCA) is used to reduce the dimensionality of the characteristic parameters. The driving segments are classified using a hybrid k-means and support vector machine (SVM) clustering algorithm. Scientific assessment criteria are studied to select the most representative driving cycle from multiple candidate driving cycles. Finally, the characteristic parameters of the Xi'an EV urban driving cycle, international standard driving cycles, and other city driving cycles are compared and analyzed. The results indicate that the Xi'an EV urban driving cycle reflects more aggressive driving characteristics than the other cycles.
\end{abstract}

\section{Introduction}

Fuel depletion, environmental disruption, and air pollution have contributed to the development of electric vehicles (EVs) [1]. The driving range calculation and state of charge estimation for EVs are generally performed based on the international standard driving cycles $[2,3]$. In the study of energy consumption prediction and energy management optimization strategies for EVs, some scholars have also adopted the international standard driving cycles [4-6]. However, the data of these international standard driving cycles were collected from internal combustion engine vehicles (ICEVs). Because of the differences in the torque characteristics, power characteristics [7-11], and braking characteristics between EVs and ICEVs, the driving cycles of EVs are significantly different from those of ICEVs [12-14]. The research on driving range calculation, state of charge estimation, energy consumption prediction, and energy management optimization strategies for $\mathrm{EV}$ under the international standard driving cycles can produce large errors. Therefore, it is important to conduct research on the driving cycles of EVs $[15,16]$.
The driving cycle is a speed-time profile that represents a typical real-world driving pattern in a certain city or region $[3,17]$. Driving cycles have a wide range of applications in the vehicle and transportation fields [18], and they are often used to simulate traffic conditions during laboratory chassis dynamometer bench tests and in automotive simulation research [3]. Moreover, these cycles serve as a standardized measurement procedure for the evaluation and certification of new vehicle models, the monitoring of exhaust emissions and fuel consumption for ICEVs, and the estimation of the driving range and energy consumption per unit mileage for EVs $[3,19]$. Because of differences in city size, road topology, road types, traffic conditions, vehicle ownership, economics, cultures, geographical features, and vehicle types, the characteristics of driving cycles in different cities and regions are different $[20,21]$. Hence, it is necessary to develop a unique driving cycle for each typical city and region. Moreover, many researchers have found that the energy consumption of an EV for a real-world driving cycle greatly differs from that based on the international standard driving cycles [19, 22-25].

Many researchers have also successfully developed realworld driving cycles, such as the Dublin driving cycle [3], 
Hong Kong driving cycle [17], California driving cycle [26], Edinburgh driving cycle [27], Hamburg driving cycle [28], Winnipeg driving cycle [29], Mashhad driving cycle [30], Beijing driving cycle, Shanghai driving cycle, Chengdu driving cycle, Chongqing driving cycle, Ningbo driving cycle, Changchun driving cycle, Jilin driving cycle, Zitong driving cycle, Jiutai driving cycle, and Mianyang driving cycle [31]. To date, no studies have focused on the development of typical urban driving cycles in northwestern China. As the core city in Northwest China, Xi'an is characterized by the comprehensive economic, cultural, traffic, and population dynamics driven by the western development in China. Furthermore, Xi'an is a typical ancient capital of China. Notably, the center of the city is the bell tower, and the first ring road was built along the ancient city wall. Xi'an has a population of 9.61 million, and the number of vehicles totals more than 3 million. The total length of urban roads is 2562 $\mathrm{km}$. Therefore, this paper takes Xi'an as an example to study the construction methodology of the EV urban driving cycle.

This paper is organized as follows. The test route selection and data collection method are presented in Section 2. The data processing procedure uses principal component analysis (PCA) to reduce the dimensionality of characteristic parameters, and the k-means and support vector machine (SVM) hybrid method is used for clustering calculations in Section 3. The driving cycle is constructed in Section 4. Section 5 compares the EV driving cycle constructed in this paper with other driving cycles. Finally, Section 6 presents the conclusions of this study.

\section{Test Route Selection and Data Collection Method}

The test routes must cover various urban road types, business and nonbusiness districts, densely populated areas and nonpopulated areas and consider the urban topological structure, driving speed, traffic flow, travel time, and origin-destination (O-D) pattern [30, 33-35]. First, the overall topological structure of urban roads in Xian was analyzed using ArcGIS software. The lengths and proportions of urban roads in Xian are shown in Figure 1. The total length of Xian urban roads is $2562 \mathrm{~km}$, including $141 \mathrm{~km}$ of expressways, $597 \mathrm{~km}$ of main roads, $1001 \mathrm{~km}$ of secondary roads, and $823 \mathrm{~km}$ of branch roads. To investigate traffic flow, 11 traffic flow monitoring points were established on various types of roads: 2 expressways, 5 main roads, 4 secondary roads, and 1 branch road. Moreover, to avoid the differences between working days and nonworking days, traffic flow monitoring tests were conducted over 14 days. The traffic flow survey results obtained are shown in Figure 2. According to the traffic flow survey results, the peak times are 7:30-9:30 and 17:30-19:30, and the off-peak times are 12:00-13:30 and 19:30-21:00 [17, 20,29-31]. Considering the abovementioned comprehensive factors, a circular road with a length of $38.4 \mathrm{~km}$ was finally selected as the test route. This route included the $11.3 \mathrm{~km}$ of expressways, $10.7 \mathrm{~km}$ of main roads, $9.4 \mathrm{~km}$ of secondary roads, and $7.0 \mathrm{~km}$ of branch roads, as shown in Figure 3. The details of the test route are shown in Table 1. Because Xian is located in a plain area, the slopes of the urban roads are
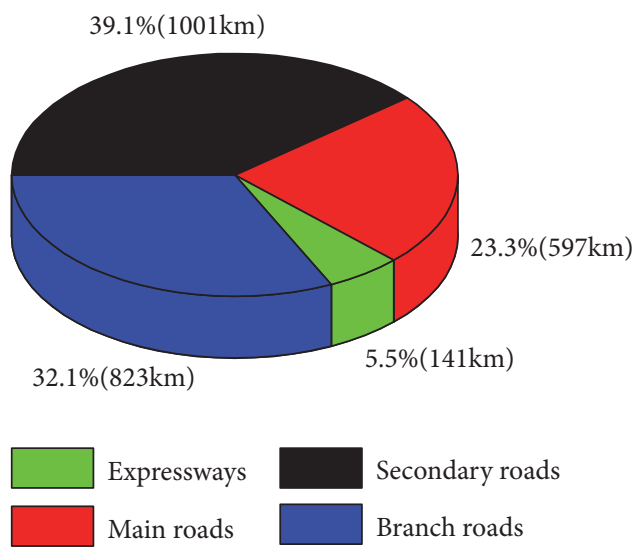

FIGURE 1: Lengths and proportions of urban road types.

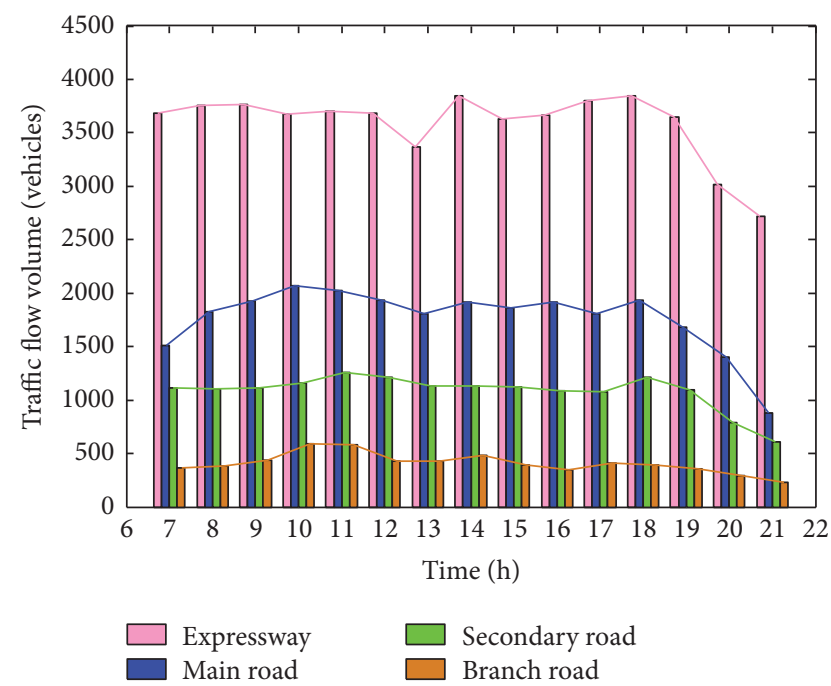

FIGURE 2: Traffic flow survey results.

mainly caused by the viaducts, and the influence of the road gradient on data acquisition is not considered in the test route selection process.

In driving cycle construction, the common data acquisition methods include the on-board measurement method and chase car method. On-board measurement method uses on-board diagnostics (OBD) installed in a test vehicle to collect trip activity information. The advantage of this approach is that the collected data can accurately represent the actual driving cycle based on large-scale studies. However, the test costs to obtain a reasonable sample size can be extremely high, and the data processing workload is large $[32,34,36]$. Chase car method is widely used to collect speed-time data from real-world driving cycles. Such method involves randomly following a target vehicle and imitating its driving pattern in the traffic stream. When the previous target vehicle stops or is lost, another tracking target is selected [37]. A global position system (GPS) is installed in the test car to collect data, and a large number of driving characteristics are simulated and sampled through the car-following process. Chase car method has been commonly adopted due to its low cost requirements [17, 27, 33, 35]. 


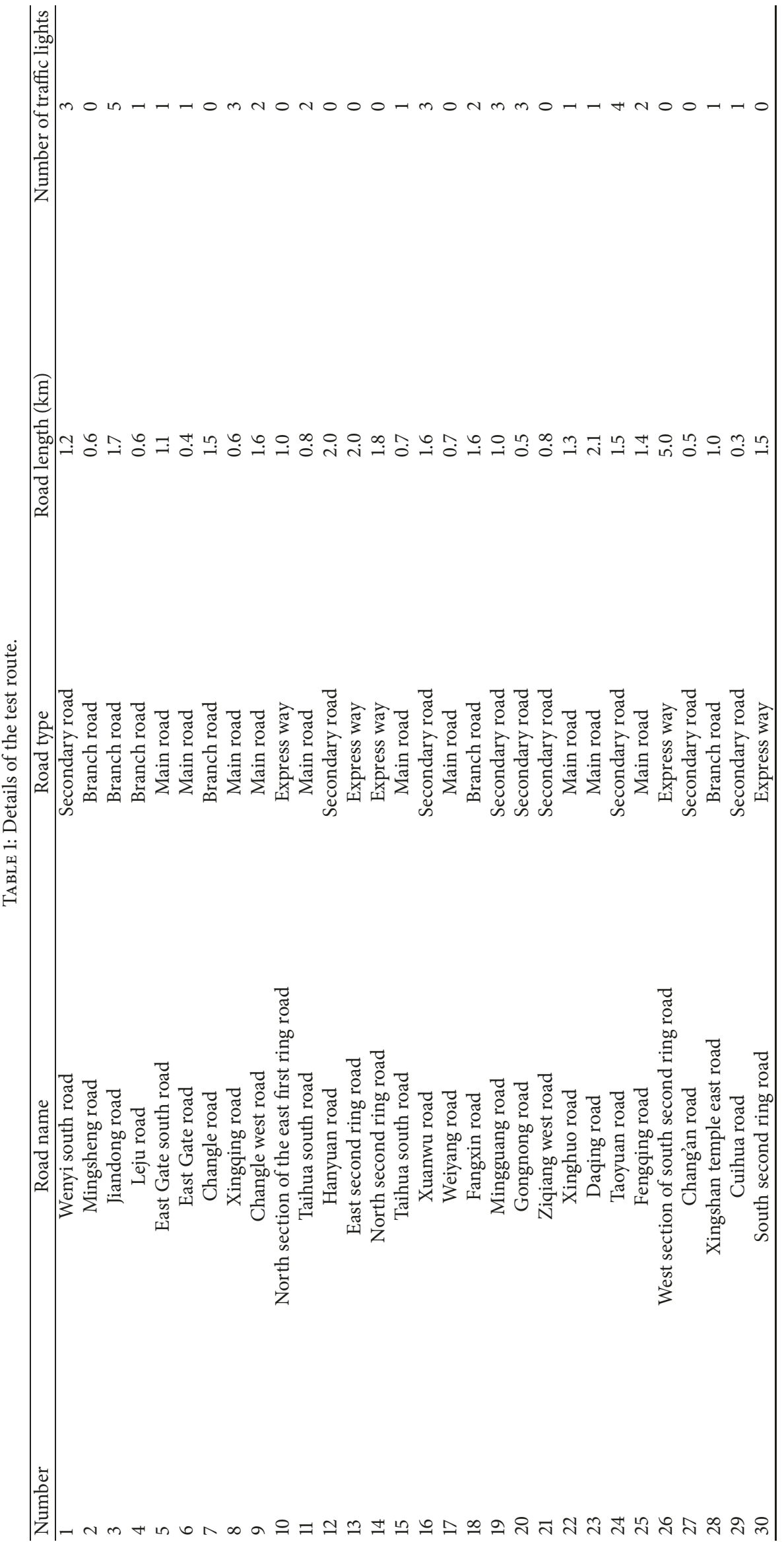



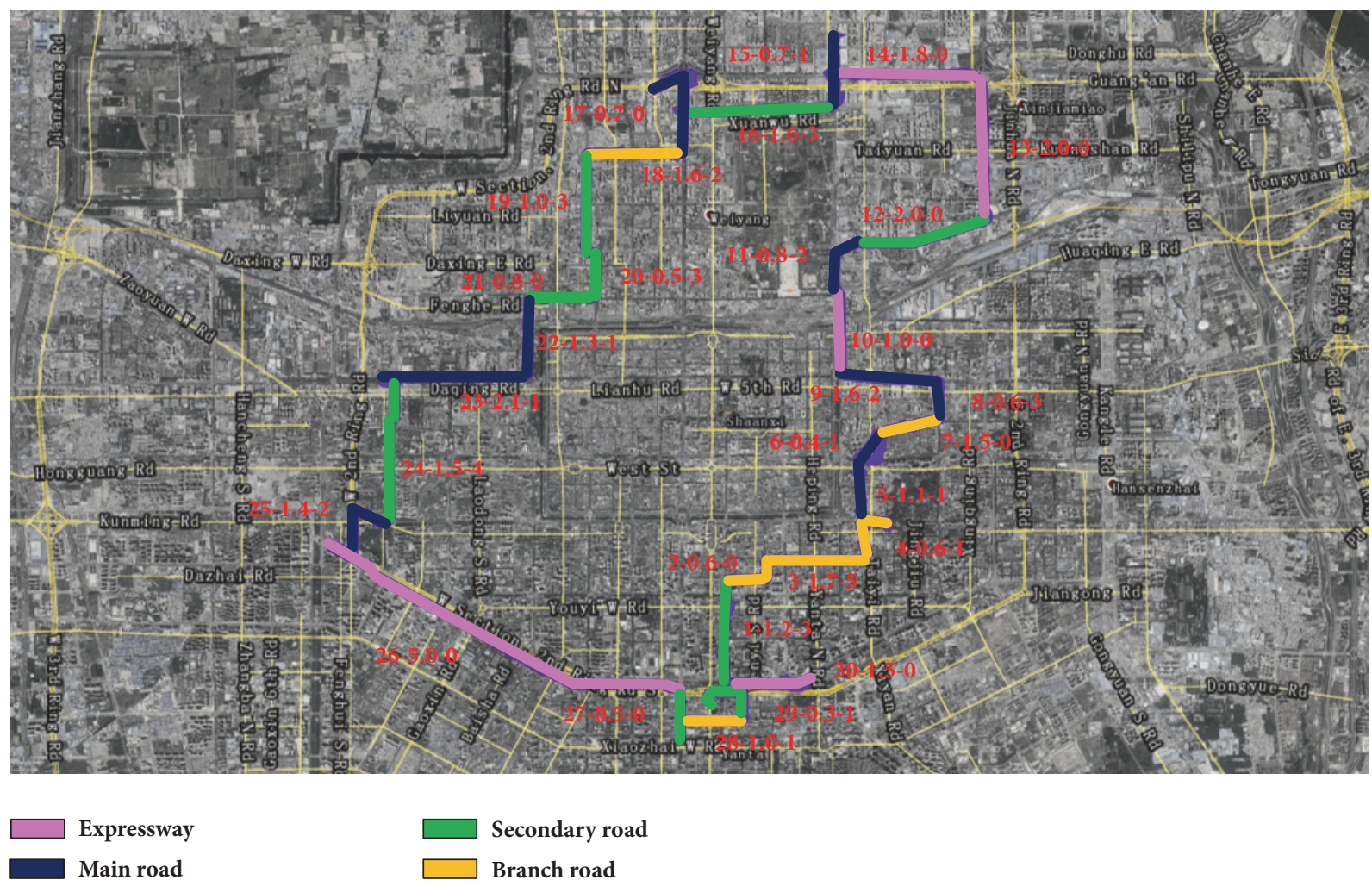

Secondary road

Branch road

Figure 3: Test route. Note: the red data in the A-B-C format represents road information, where A represents the serial number of the roads, $B$ represents the length of the roads, and $C$ represents the number of traffic lights.

Considering on-board measurement method and chase car method has distinct merits and demerits, and this paper used a hybrid method of on-board measurement method and chase car method to collect test data. When an available $\mathrm{EV}$ was driving on the preset test route, the test vehicle chased it and imitated its driving pattern; when no target EV was available, the driving patterns of the test vehicle were collected. The GPS signal is easily influenced by the urban buildings, which can cause signal loss and data spikes; therefore, both GPS and OBD were used to collect driving pattern data. Speed-time data obtained by OBD were mainly used to supplement and improve abnormal GPS data. Moreover, 14 trained professional drivers were selected to minimize the influence of the driver on the collected data. In addition, a BYD E6 pure EV, which is the most commonly owned EV in the market, was selected as the test vehicle. The technical characteristics of the test EV are shown in Table 2. The experimental equipment installed in the test vehicle mainly included a GPS, OBD, a gyroscope, a driving recorder, a $12-\mathrm{V}$ lead-acid battery, and a power inverter. The GPS recorded the speed, time, and distance of each trip. The OBD recorded the speed, time, distance, and battery state of charge. Additionally, the gyroscope recorded the acceleration signal and road gradient, and the driving recorder was used to collect traffic condition and chased vehicle information. Finally, 12-V lead-acid battery and power inverter were used to power the test equipment. The test equipment is shown in Figure 4. All data were recorded at a constant sampling frequency of $1 \mathrm{~Hz}$ [38-40]. Driving data was collected by test vehicles moving along preset routes under real-world traffic conditions. Moreover, to consider the effect of the traffic flow and travel time on the test results, a 14-day test was conducted. The daily test periods were the morning peak from 7:30 to 9:30, the midday off-peak from 12:00 to 13:30, the afternoon peak from 17:30 to 19:30, and the evening off-peak from 19:30 to 21:00. The tests were conducted under clear weather conditions, on dry roads, and at wind speeds less than $1 \mathrm{~m} / \mathrm{s}$. Data collection ceased in cases of abnormal traffic conditions [30]. Test data were collected for a total of 56 trips totaling approximately 428 hours.

\section{Data Processing}

In the data processing procedure, the raw data were first denoised and smoothed by using a wavelet decomposition and reconstruction method. Then, the preprocessed data were partitioned into 36388 kinematic segments according to (1). In addition, a PCA algorithm was adopted to reduce the dimensionality of the characteristic parameters. Finally, the k-means and SVM hybrid clustering algorithm was used to classify the kinematic segments that were used to construct the driving cycle.

$$
\begin{array}{cc}
\text { acceleration } \quad a \geq 0.15 \mathrm{~m} / \mathrm{s}^{2} \\
\text { deceleration } \quad a \leq-0.15 \mathrm{~m} / \mathrm{s}^{2} \\
\text { uniform } \quad v \geq 2 \mathrm{~m} / \mathrm{s} \cap-0.15 \mathrm{~m} / \mathrm{s}^{2}<a<0.15 \mathrm{~m} / \mathrm{s}^{2} \\
\text { idling } \quad v<2 \mathrm{~m} / \mathrm{s} \cap-0.15 \mathrm{~m} / \mathrm{s}^{2}<a<0.15 \mathrm{~m} / \mathrm{s}^{2}
\end{array}
$$

where $a$ is acceleration and $v$ is speed. 
TABLE 2: Technical characteristics of the test EV.

\begin{tabular}{lr}
\hline Characteristic parameter & Value \\
\hline Curb weight $(\mathrm{kg})$ & 2380 \\
Mass $(\mathrm{kg})$ & 2755 \\
Length $(\mathrm{mm})$ & 4560 \\
Width $(\mathrm{mm})$ & 1822 \\
Height $(\mathrm{mm})$ & 1630 \\
Wheel based $(\mathrm{mm})$ & 2830 \\
Front/rear track width $(\mathrm{mm})$ & $1585 / 1560$ \\
Centroid height $(\mathrm{mm})$ & 640 \\
Maximum speed $(\mathrm{km} / \mathrm{h})$ & 140 \\
Maximum endurance mileage $(\mathrm{km})$ & 400 \\
Rated voltage $(\mathrm{V})$ & 600 \\
Maximum torque $(\mathrm{Nm})$ & 450 \\
Maximum power $(\mathrm{kW})$ & 120 \\
\hline
\end{tabular}

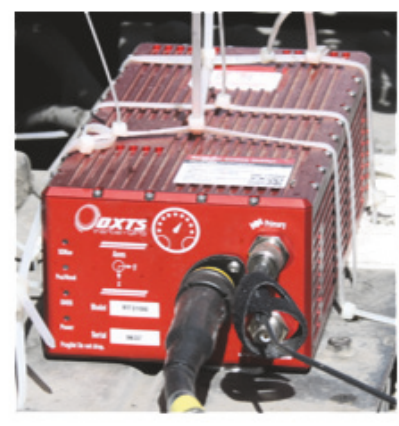

Gyroscope

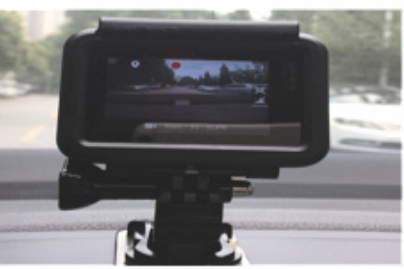

Driving recorder

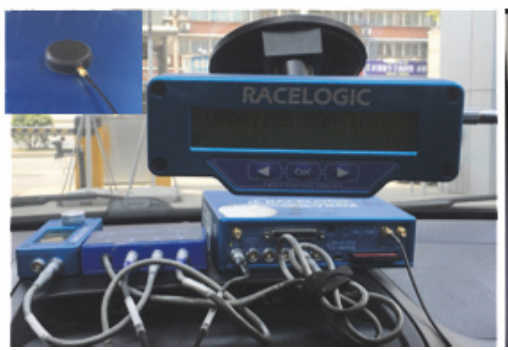

GPS

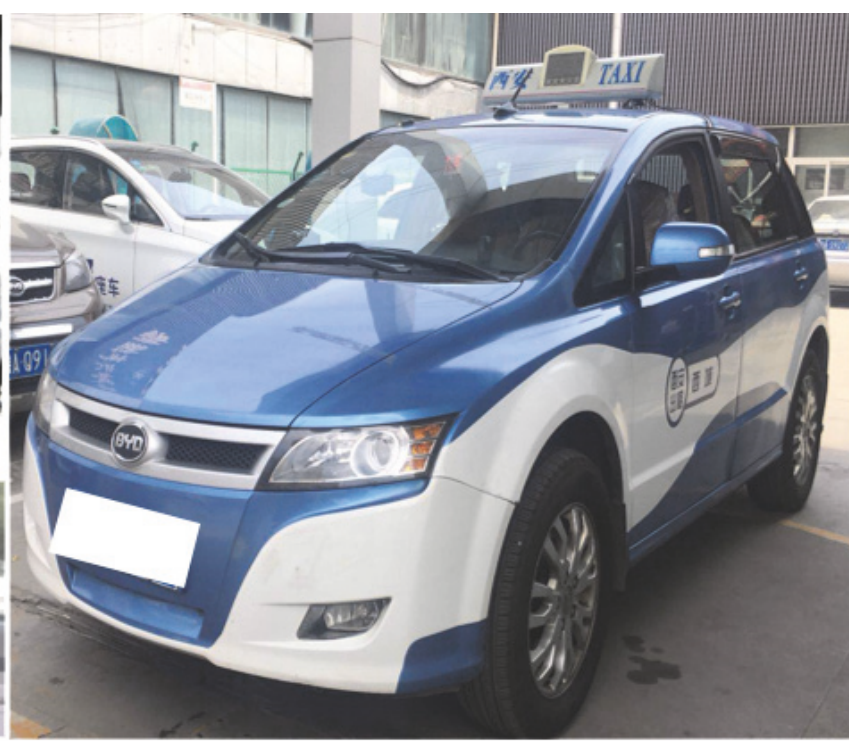

Test EV

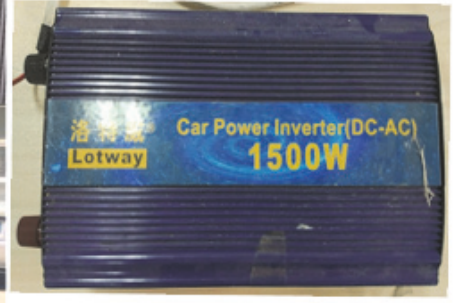

Power inverter

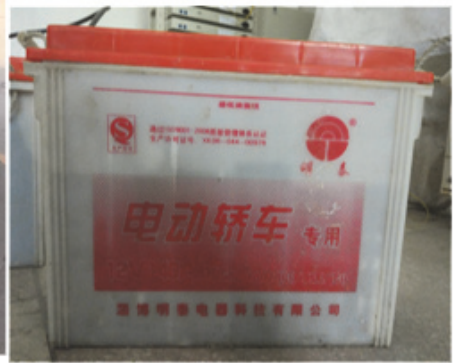

$12 \mathrm{~V}$ lead-acid battery

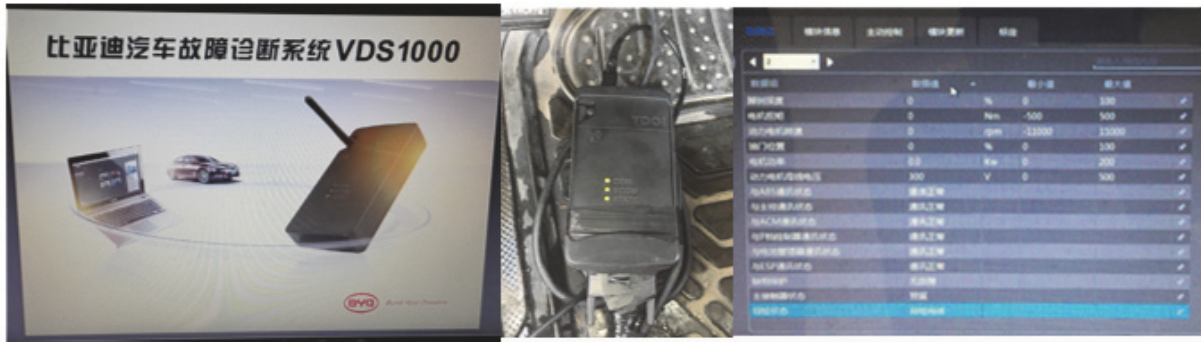

OBD

FIgURE 4: Test equipment.

3.1. Reduction of the Dimensionality of Characteristic Parameters Based on PCA. PCA was proposed and applied by statisticians K. Pearson and H. Hotelling in 1901 [41, 42]. PCA is a multivariate statistical method that transforms a large number of correlated variables into a few uncorrelated principal components through orthogonal transformation and can maintain the original variable information as much as possible. Generally, we use characteristic parameters to describe the vehicle motion state. If all the characteristic parameters are used for classification, it will increase both the computational complexity and the difficulty of analysis [41, 42]. Although each parameter characterizes different motion information, the parameters are not independent, and some parameters can be expressed by a combination of several 
other parameters. Therefore, we use the PCA algorithm to reduce the dimensionality of the characteristic parameters $[41,42]$.

According to the existing literature, eight characteristic parameters are selected: the maximum speed, minimum speed, average speed, standard deviation of speed, maximum acceleration, maximum deceleration, average acceleration, and standard deviation of acceleration $[30,33,36]$.

We assume that the sample size is $n$, the number of observed parameters is $p$, and the sample observation matrix is $A=\left[a_{i j}\right]_{n \times p}$.

$$
A_{n \times p}=\left[\begin{array}{cccc}
a_{11} & a_{12} & \cdots & a_{1 p} \\
a_{21} & a_{22} & \cdots & a_{2 p} \\
\vdots & \vdots & & \vdots \\
a_{n 1} & a_{n 2} & \cdots & a_{n p}
\end{array}\right]
$$

where $a_{i j}$ is the $j$-th characteristic parameter of the $i$-th kinematic segment.

The principal component expressions obtained after orthogonal transformation using the PCA are as follows:

$$
\begin{gathered}
y_{1}^{\prime}=e_{1}^{T} X=e_{1-1} x_{1}+e_{1-2} x_{2}+\cdots+e_{1-p} x_{p} \\
y_{2}^{\prime}=e_{2}^{T} X=e_{2-1} x_{1}+e_{2-2} x_{2}+\cdots+e_{2-p} x_{p} \\
\vdots \\
y_{p}^{\prime}=e_{p}^{T} X=e_{p-1} x_{1}+e_{p-2} x_{2}+\cdots+e_{p-p} x_{p}
\end{gathered}
$$

$$
\left[\begin{array}{l}
Y_{1} \\
Y_{2} \\
Y_{3} \\
Y_{4} \\
Y_{5} \\
Y_{6} \\
Y_{7} \\
Y_{8}
\end{array}\right]=\left[\begin{array}{cccc}
0.567 & 0.499 & 0.562 & 0.158 \\
-0.151 & -0.046 & -0.096 & -0.196 \\
-0.007 & -0.341 & -0.167 & 0.574 \\
-0.220 & 0.239 & -0.006 & -0.650 \\
-0.006 & 0.043 & -0.041 & 0.155 \\
-0.017 & 0.019 & 0.000 & 0.054 \\
-0.212 & 0.750 & -0.535 & 0.304 \\
-0.749 & 0.106 & 0.600 & 0.256
\end{array}\right.
$$

$\left.\begin{array}{cccc}0.203 & 0.074 & 0.149 & 0.143 \\ 0.443 & 0.599 & 0.579 & -0.193 \\ 0.395 & -0.117 & 0.149 & 0.579 \\ 0.139 & -0.140 & -0.001 & 0.658 \\ -0.484 & 0.734 & -0.210 & 0.393 \\ -0.589 & -0.245 & 0.759 & 0.114 \\ 0.067 & -0.056 & 0.000 & -0.074 \\ 0.019 & -0.007 & -0.020 & -0.036\end{array}\right] \times\left[\begin{array}{c}X_{1} \\ X_{2} \\ X_{3} \\ X_{4} \\ X_{5} \\ X_{6} \\ X_{7} \\ X_{8}\end{array}\right]$
calculated. in (6).

The principal components corresponding to the eigenvalues whose cumulative variance contributions ratio are greater than $90 \%$ are selected to form the comprehensive evaluation index that encompasses $90 \%$ of the entire data information.

The number of principal components with cumulative variance contribution ratio exceeding $90 \%$ is obtained, where $Y_{i}=e_{i}^{T} X, i=1,2, \ldots, k(k \leq p)$. Additionally, the principal component expression and the principal component score are

The calculated principal component expression is shown

where $Y_{1}, Y_{2}, \ldots$, and $Y_{8}$ are the first, second, .., and eighth principal components, respectively; $X_{1}, X_{2}, \ldots$, and $X_{8}$ represent maximum speed, minimum speed, average speed, standard deviation of speed, maximum acceleration, maximum deceleration, average acceleration, and standard deviation of acceleration, respectively.

The PCA algorithm is used to reduce the dimensionality of the characteristic parameters. The principal component variance, variance contribution ratio, and the cumulative variance contribution ratio are shown in Table 3. Notably, from the first principal component to the eighth principal component, as the principal component variance decreases, the amount of information contained in the principal component gradually decreases. The first principal component
$Y_{1}$ contains the most information, in this case, $36.15 \%$ of the original indicator information. The second principal component $Y_{2}$ contains $32.94 \%$ of the original indicator information, and the third principal component $Y_{3}$ contains $28.50 \%$ of the original indicator information. The cumulative contribution ratio of the first three principal components reaches $97.59 \%$; therefore, they essentially encompass all the original indicator information. Thus, to simplify the problem and reduce the complexity of the analysis, the first three principal components are selected as the characteristic parameters for clustering analysis. The principal component score matrix is shown in Table 4 . These scores are calculated for the first three principal components of 36388 kinematic segments. The component matrix is shown in Table 5, which 
TABle 3: PCA results.

\begin{tabular}{lccc}
\hline $\begin{array}{l}\text { Number of principal } \\
\text { component }\end{array}$ & $\begin{array}{c}\text { Principal component } \\
\text { variance }\end{array}$ & $\begin{array}{c}\text { Variance contribution rate } \\
\text { /\% }\end{array}$ & $\begin{array}{c}\text { Cumulative variance } \\
\text { contribution rate /\% }\end{array}$ \\
\hline 1 & 2.892 & 36.15 & 36.15 \\
2 & 2.635 & 32.94 & 69.09 \\
3 & 2.280 & 28.50 & 97.59 \\
4 & 0.182 & 2.27 & 99.86 \\
5 & 0.005 & 0.06 & 99.92 \\
6 & 0.004 & 0.05 & 99.97 \\
7 & $9.9 \mathrm{e}-4$ & 0.02 & 99.99 \\
8 & $5.9 \mathrm{e}-4$ & 0.01 & 100.00 \\
\hline
\end{tabular}

TAble 4: Principal component score matrix.

\begin{tabular}{lccc}
\hline $\begin{array}{l}\text { Segment } \\
\text { number }\end{array}$ & $\begin{array}{c}\text { Principal } \\
\text { component } 1\end{array}$ & $\begin{array}{c}\text { Principal } \\
\text { component 2 }\end{array}$ & $\begin{array}{c}\text { Principal } \\
\text { component 3 }\end{array}$ \\
\hline 1 & 2.569 & 0.748 & 0.271 \\
2 & 1.909 & 1.510 & -0.645 \\
3 & 1.998 & 0.898 & -0.158 \\
4 & 1.853 & 1.552 & 0.188 \\
5 & 1.829 & 0.467 & -0.316 \\
$\vdots$ & $\vdots$ & $\vdots$ & $\vdots$ \\
10000 & -0.459 & 1.424 & -0.054 \\
10001 & 0.026 & 0.102 & 1.151 \\
10002 & 0.306 & -1.141 & 0.380 \\
10003 & 0.217 & 0.946 & 0.817 \\
10004 & -0.644 & 1.510 & -0.258 \\
$\vdots$ & $\vdots$ & $\vdots$ & $\vdots$ \\
36384 & 1.972 & 0.619 & 0.470 \\
36385 & 0.865 & 1.777 & -1.059 \\
36386 & 1.472 & 0.200 & 0.742 \\
36387 & 2.110 & -1.821 & -0.838 \\
36388 & 2.670 & 0.368 & 0.373 \\
\hline
\end{tabular}

TABle 5: Component matrix.

\begin{tabular}{lccc}
\hline Characteristic parameters & $\begin{array}{c}\text { Principal } \\
\text { component 1 }\end{array}$ & $\begin{array}{c}\text { Principal } \\
\text { component 2 }\end{array}$ & $\begin{array}{c}\text { Principal } \\
\text { component 3 }\end{array}$ \\
\hline maximum speed & 0.965 & -0.245 & -0.010 \\
minimum speed & 0.848 & -0.074 & -0.514 \\
average speed & 0.955 & -0.155 & -0.252 \\
standard deviation of speed & 0.268 & -0.317 & 0.866 \\
maximum acceleration & 0.346 & 0.720 & 0.597 \\
maximum deceleration & 0.125 & 0.973 & -0.177 \\
average acceleration & 0.254 & 0.939 & 0.225 \\
standard deviation of acceleration & 0.243 & -0.313 & 0.874 \\
\hline
\end{tabular}




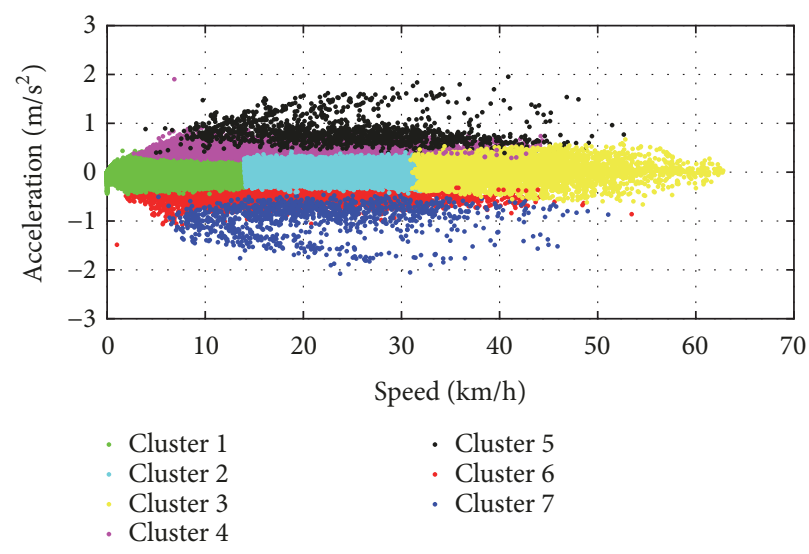

Figure 5: k-means clustering result.

displays the correlation coefficient between the principal component and the original characteristic parameter.

\subsection{Clustering Based on the k-Means and SVM Hybrid Algorithm}

3.2.1. Clustering Based on k-Means. The k-means algorithm has been widely used in cluster computing in the existing literature $[3,4,19,24,43]$. The $\mathrm{k}$-means clustering algorithm uses the Euclidean distance between a sample and cluster center as a criterion for similarity determination, and it has the advantages of efficiency and simplicity [19, 43]. The Euclidean distance is calculated as shown in (7).

$$
d_{i j}=\sqrt{\sum_{k=1}^{p}\left(x_{i k}-x_{j k}\right)^{2}}
$$

where $P$ is the number of characteristic parameters and $x_{i k}$ and $x_{j k}$ are the $k$-th characteristic parameters of the $i$-th sample and the $j$-th sample, respectively.

The number $k$ of clusters in the $\mathrm{k}$-means algorithm has an important influence on the clustering results, but generally, an accurate value of $k$ is initially unknown $[44,45]$. If the number of clusters is greater than the true value, the algorithm wrongly divides the same class of data into multiple classes, which will cause the clustering result boundaries to be blurred [46]. Conversely, merging different classes of data into one class will result in a decrease in the compactness of the cluster [47]. Therefore, clustering stability is generally used to determine the $k$ value [48]. The concept of the approach is that if repeated clustering is performed for the same sample data, then a suitable $k$ value should produce the same clustering results. In other words, stability is viewed as an indication of whether the $k$ value fits the data. We repeated the clustering stability simulation test and finally determined that the number of clusters was seven. The classification results of the k-means clustering algorithm are shown in Figure 5.

The analysis of the k-means clustering effect shows that when the distances between the segment and other cluster centers are large enough, and the characteristic parameters of the segment are close to those of a certain class, the clustering effect is good. In contrast, when the distance between the segment and all cluster centers is similar and the characteristic parameters of the segment are significantly different from those of most of the segments in the class, the clustering effect is poor. There are two main reasons for these results. First, k-means is a hard clustering algorithm. When clustering involves multiple classes or the distance between cluster centers is small, the clustering effect is poor, and it is easy to reach local optima that cannot be incrementally clustered. Second, the convergence condition of the k-means clustering algorithm is iterated until the cluster center no longer changes. This approach may cause the data within the class to be very similar but does not fully consider the distance between classes; therefore, only local optima are guaranteed, and the global optimization is not achieved.

3.2.2. Clustering Based on the k-Means and SVM Hybrid Algorithm. The SVM method was first proposed by Cortes and Vapnik in 1995 and has significant advantages in solving nonlinear and high-dimensional pattern recognition problems $[49,50]$. The SVM method is based on the VapnikChervonenkis dimensional statistical learning theory and is an approximate implementation of minimizing structural risk. The basic principle of SVM is to establish an optimal classification hyperplane that can not only separate samples without errors, but also maximize the classification interval [50]. A schematic diagram of the optimal hyperplane is shown in Figure 6. SVM has been widely used for classification identification due to its many advantages, such as a high level of robustness and strong generalization ability.

We assume that the size of the sample set is $l$ and that the sample set consists of two classes: $S=\left\{\left(x_{i}, y_{i}\right), i=\right.$ $\left.1,2, \cdots, l, x_{i} \in R^{d}, y_{i} \in\{+1,-1\}\right\}$. If $x_{i}$ belongs to the first class, $y_{i}=1$; otherwise, $y_{i}=-1$. If the sample can be correctly divided into two classes using a classification hyperplane, then the sample is linearly separable and satisfies (8).

$$
\begin{aligned}
w x_{i}+b & \geq 1, \\
y_{i} & =1
\end{aligned}
$$




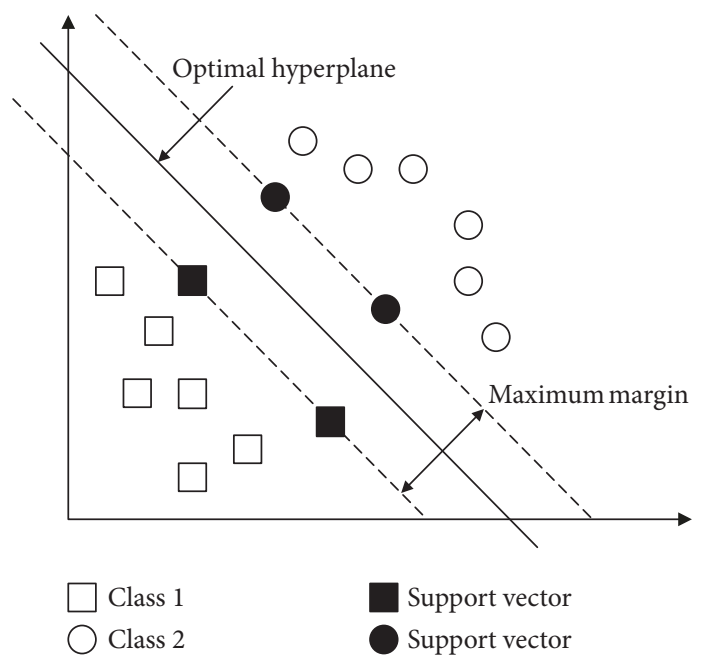

FIGURE 6: Schematic diagram of the optimal hyperplane.

$$
\begin{aligned}
w x_{i}+b & \leq-1, \\
y_{i} & =-1, \\
& \quad i=1,2, \cdots, l
\end{aligned}
$$

where $x_{i}$ is the sample data, $y_{i}$ is a decision attribute, $w$ is the normal vector of the hyperplane, and $b$ is the offset of the classification straight line.

If the interval from the sample point to the classification hyperplane is $\varepsilon=\left|w x_{i}+b\right|=1$, the distance between two types of samples is $2 /\|w\|$. To select an optimal classification hyperplane from a large number of classification hyperplanes and separate the samples of different classes as much as possible, the distance from the sample set to the classification hyperplane is maximized. Therefore, the optimization goal is to find the optimal classification hyperplane under the constraint of (9).

$$
\begin{array}{ll}
\min & \frac{\|w\|^{2}}{2} \\
\text { s.t. } & y_{i}\left(w x_{i}+b\right) \geq 1, \quad i=1,2, \cdots, l
\end{array}
$$

The above problem can be transformed into a dual problem according to the Lagrange theory and then solved with a quadratic programming method. In the linear inseparability problem, the nonlinear mapping of $\Phi: R^{d} \longrightarrow H$ is used to map the original input space samples to the feature space $H$. Then, the optimal classification hyperplane is constructed in the high-dimensional feature space $H$. The dual problem after mapping to the high-dimensional feature space becomes (10).

$$
\begin{array}{ll}
\max & Q(a)=\sum_{i=1}^{l} a_{i}-\frac{1}{2} \sum_{i=1}^{l} \sum_{j=1}^{l} a_{i} a_{j} y_{i} y_{j} K\left(x_{i}, x_{j}\right) \\
\text { s.t. } & \begin{cases}\sum_{i=1}^{l} a_{i} y_{i}=0 & i=1,2, \cdots, l \\
0 \leq a_{i} \leq C,\end{cases}
\end{array}
$$

where $a_{i}>0, i=1,2, \cdots, l$ is the Lagrange coefficient and $K\left(x_{i}, x_{j}\right)$ is the kernel function that satisfies the Mercer condition. $C$ is a penalty factor used to control penalty degree for misclassified samples.

Assuming that $a^{*}=\left(a_{1}^{*}, a_{2}^{*}, \cdots, a_{l}^{*}\right)^{T}$ is the solution of (10), then the final optimal classification function can be obtained as shown in (11).

$$
f(x)=\operatorname{sgn}\left(\sum_{i=1}^{l} a_{i}^{*} y_{i} K\left(x_{i}, x\right)+b^{*}\right)
$$

This paper builds a multiclassification model based on SVM to classify the driving segments. The specific classification processes include training set screening, kernel function parameter optimization, classification prediction, and clustering result evaluation.

The first step is training set screening. Because a SVM is a supervised learning algorithm, selecting an appropriate training set before classification is extremely important. To improve the classification accuracy and efficiency, the optimal segments were selected from the $\mathrm{k}$-means clustering results as the SVM training set, and the remaining segments were used as the testing set. The selection principles of the optimal segments are as follows. We selected an appropriate number of training sets to avoid under-learning and over-learning issues. Moreover, we selected representative segments from the k-means clustering results, and these segments were as close to a cluster center as possible and as far from the other cluster centers as possible. According to the above principles, 2353 representative segments were selected as the training set of the SVM, and the remaining segments were used as the testing set. Additionally, all segments were normalized to eliminate the influence of the dimensions on the classification results.

The second step is kernel function parameter optimization. Kernel functions can map the sample data in the original low-dimensional space to a high-dimensional feature space and transform them into linearly separable data. Meanwhile, the optimal classification hyperplane in the high-dimensional 


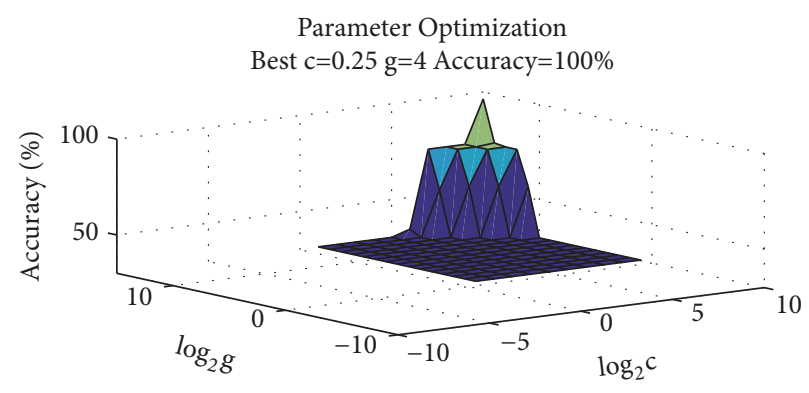

FIgURE 7: Optimization results.

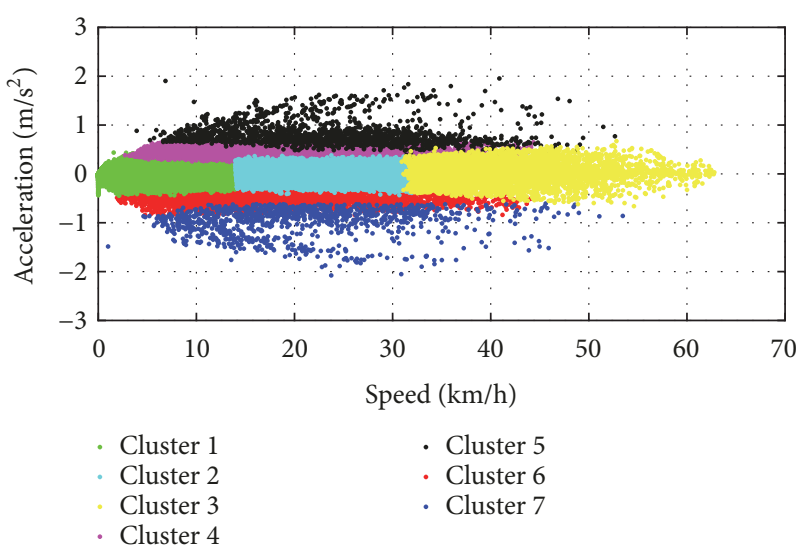

FIGURE 8: k-means and SVM hybrid model clustering results.

space can be obtained. Because the radial basis kernel function $(\mathrm{RBF})$ can precisely express the features of the training set, accurately reflect the structure feature of the high-dimensional space, effectively control the dimension of the model solution set, and obtain the global optimal solution, this paper uses a RBF as the basic kernel function of the SVM.

$$
K\left(x, x_{i}\right)=\exp \left(- \text { gamma }\left\|x_{i}-x\right\|^{2}\right)
$$

where $\left\|x-x_{i}\right\|$ is the two-norm distance, $x_{i}$ is the support vector, $x$ is the predicted sample, and gamma is the kernel function parameter $g$.

Based on $K$-fold cross validation method, this paper adopts a grid search algorithm to obtain the optimal parameters $c$ and $g$. The optimization results are shown in Figure 7. When $c=0.25$ and $g=4.0$, classification recognition accuracy reaches a maximum of $100 \%$.

The third step in the proposed method involves classification prediction and clustering result evaluation. The SVM model was trained using the optimal parameters. The clustering results of driving segments using the k-means and SVM hybrid model are shown in Figure 8.

To evaluate the clustering results, this paper introduces two indicators: compactness and separation [47, 51].

Compactness (CP) is an internal cluster evaluation criterion that uses the norm distance between all data sets in each cluster and the cluster center to evaluate the compactness of the cluster. A small CPvalue indicates that the data within the cluster are similar or close to one another.

$$
\overline{C P_{i}}=\frac{1}{\left|\Omega_{i}\right|} \sum_{x_{i} \in \Omega_{i}}\left\|x_{i}-w_{i}\right\|
$$

where $\Omega_{i}$ is the $i$ th cluster, $w_{i}$ is the cluster center in $\Omega_{i}, x_{i}$ represents the data in $\Omega_{i}$, and $\left|\Omega_{i}\right|$ represents the quantity of data in $\Omega_{i}$. As a global measure of compactness, the average of all clusters is calculated as follows.

$$
C P=\frac{1}{K} \sum_{k=1}^{K} \overline{C P_{k}}
$$

where $K$ is the number of clusters.

Separation (SP) is an external evaluation criterion between clusters that uses the average Euclidean distance between each two cluster centers to evaluate the degree of separation of the clusters. A high $S P$ value indicates that the distance between clusters is large.

$$
S P=\frac{2}{K^{2}-K} \sum_{i=1}^{K} \sum_{j=i+1}^{K}\left\|w_{i}-w_{j}\right\|_{2}
$$

Table 6 gives the calculation results for $C P$ and SP. A comparison of the values indicates that the k-means and SVM hybrid clustering results have small $C P$ and large $S P$ values; therefore, the clustering results with the k-means and SVM hybrid model are significantly better than those of the kmeans alone.

The categorized driving segment characteristics are shown in Table 7 and include low constant speed driving segments, medium constant speed driving segments, high constant speed driving segments, weak acceleration driving segments, strong acceleration driving segments, weak deceleration driving segments, and strong deceleration driving segments.

\section{Driving Cycle Construction}

The driving cycle is constructed by connecting the most representative driving segments according to predetermined rules until the driving cycle duration is reached. Generally, the duration of the general international standard driving cycles and real-world representative driving cycles is between 
TABLE 6: The calculation results of $C P$ and $S P$.

\begin{tabular}{lcc}
\hline Calculation results & k-means & k-means and SVM \\
\hline$C P$ & 1.393 & 1.317 \\
$S P$ & 4.954 & 5.242 \\
\hline
\end{tabular}

TABLE 7: Driving segment characteristics.

\begin{tabular}{|c|c|c|c|c|}
\hline Category number & $\begin{array}{c}\text { The number of } \\
\text { segments }\end{array}$ & Average speed & $\begin{array}{c}\text { Average } \\
\text { acceleration }\end{array}$ & Definition \\
\hline 1 & 10914 & 5.47 & -0.008 & low constant speed driving segments \\
\hline 2 & 9238 & 22.62 & -0.006 & medium constant speed driving segments \\
\hline 3 & 6503 & 40.54 & 0.007 & high constant speed driving segments \\
\hline 4 & 3729 & 18.75 & 0.463 & weak acceleration driving segments \\
\hline 5 & 1341 & 24.41 & 0.840 & strong acceleration driving segments \\
\hline 6 & 3573 & 18.00 & -0.489 & weak deceleration driving segments \\
\hline 7 & 1090 & 21.38 & -0.946 & strong deceleration driving segments \\
\hline
\end{tabular}

TABLE 8: Time proportion and length of seven driving segments.

\begin{tabular}{lcc}
\hline Driving segments & Time proportion (\%) & Time length (s) \\
\hline 1 & 30.53 & 366 \\
2 & 13.98 & 168 \\
3 & 12.51 & 150 \\
4 & 14.28 & 171 \\
5 & 7.84 & 94 \\
6 & 14.72 & 177 \\
7 & 6.14 & 74 \\
\hline
\end{tabular}

$600 \mathrm{~s}$ and $1800 \mathrm{~s}$. Therefore, according to the Hong Kong, Colombo, and Sydney driving cycles, the duration of the Xian $\mathrm{EV}$ urban driving cycle in this paper is set to $1200 \mathrm{~s}[17,33$, 36,43 . Then, the duration of each driving segment class in the constructed Xian EV urban driving cycle is determined based on experimental data. First, this paper calculates the cumulative time of the seven driving segment classes in the collected experimental data and determines the time proportions of the seven driving segment classes. As shown in Table 8 , the time proportions of the seven driving segment classes are $30.53 \%, 13.98 \%, 12.51 \%, 14.28 \%, 7.84 \%, 14.72 \%$, and $6.14 \%$, respectively. Then, according to the time proportions of the seven driving segment classes in the experimental data, the time length of the seven driving segment classes in the constructed Xi'an representative EV urban driving cycle is determined. Their time lengths are 366 s, 168 s, 150 s, 171 s, $94 \mathrm{~s}, 177 \mathrm{~s}$, and $74 \mathrm{~s}$. In the process of constructing the driving cycle, we first randomly select a driving segment of no more than $5 \mathrm{~s}$ as the initial segment. Then, according to the following principles, the most representative driving segments are selected. The selection principle of representative driving segments is as follows: (1) the selected driving segment should be as close as possible to the cluster center; (2) the difference between the final speed of the previous driving segment and the initial speed of the current driving segment is less than $1 \mathrm{~km} / \mathrm{h}$; (3) the selection of the driving segment is without replacement. Finally, the selected current driving segment is linked to the previous driving segment until the time length of each driving segment class is reached. This approach yields a constructed candidate driving cycle.

According to the test data and classification results, the time proportion and length of the seven driving segments are shown in Table 8.

Considering the randomness in the construction process of the driving cycle, one construction result is difficult to fully represent the Xian EV urban driving cycle. Therefore, the construction process is repeated to generate a large number of candidate driving cycles. Moreover, the scientific assessment criteria are set, and the most representative driving cycle is selected from candidate driving cycles to form the Xian EV urban driving cycle.

The assessment criteria flow diagram is shown in Figure 9. First, the average speed, maximum speed, average acceleration, average deceleration, standard deviation of acceleration, proportion of acceleration, proportion of deceleration, proportion of uniform speed, and proportion of idling are selected as assessment parameters $[17,37]$. Then, we calculate the relative error (RE) of the assessment parameters of the candidate driving cycles and the overall test data and select the driving cycles for which the RE of all the assessment parameters is less than $10 \%$. Finally, the mean relative error (MRE) is calculated, and the candidate driving cycle with the minimum MRE is selected. If there is more than one candidate driving cycle with the same minimum MRE, the 


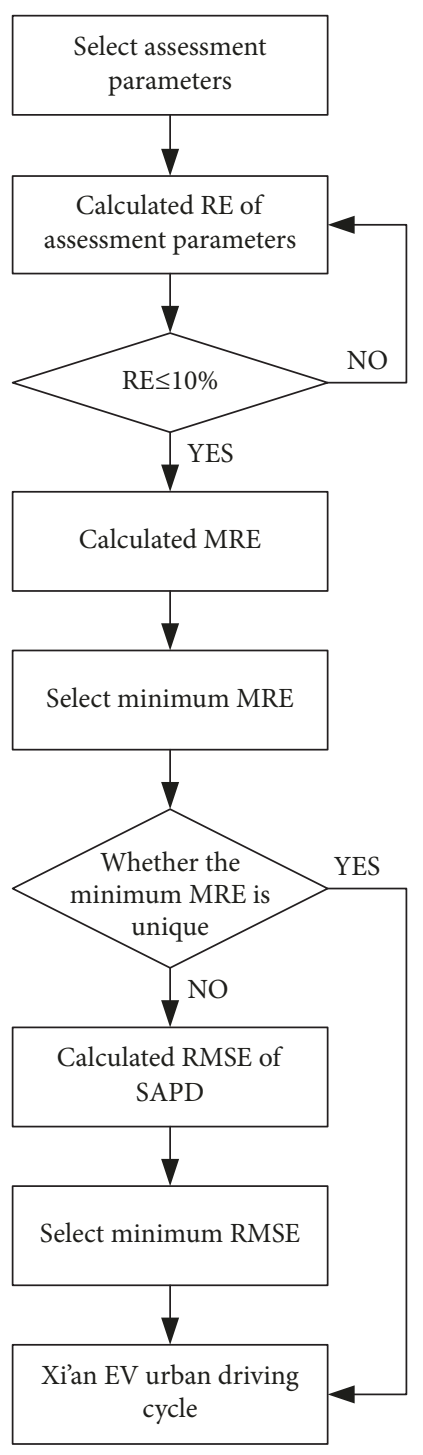

Figure 9: Assessment criteria flow diagram.

root mean square error (RMSE) of the speed-acceleration probability distribution (SAPD) is calculated. The driving cycle with the minimum RMSE is then selected as the most representative Xian EV urban driving cycle.

$$
R E=\left(\frac{\alpha_{c}-\alpha_{t}}{\alpha_{t}}\right) \times 100 \%
$$

where $\alpha_{c}$ and $\alpha_{t}$ are the assessment parameters of the candidate driving cycles and test data, respectively.

$$
M R E=\frac{1}{n} \sum_{i=1}^{n}\left(\frac{\alpha_{c}-\alpha_{t}}{\alpha_{t}}\right)
$$

where $n$ is the number of all assessment parameters.

$$
R M S E=\sqrt{\frac{1}{M \times N} \sum_{j=1}^{M} \sum_{i=1}^{N}\left(x_{i j}-y_{i j}\right)^{2}}
$$

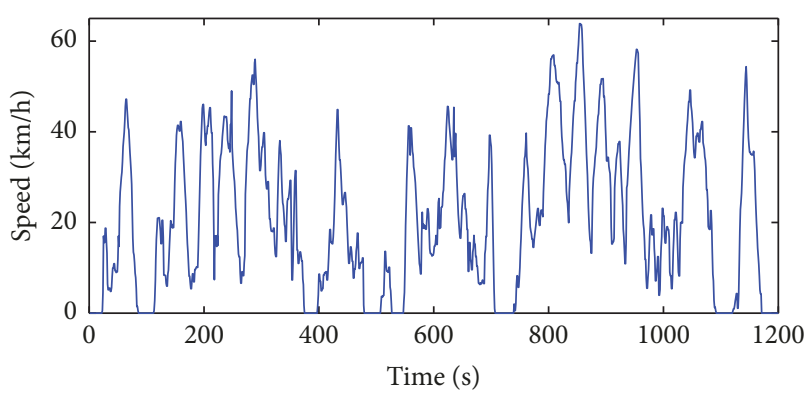

FIgURE 10: Xian EV urban driving cycle.

where $N$ and $M$ are the numbers of speed bins and acceleration bins, respectively, and $x_{i j}$ and $y_{i j}$ are the frequency values of the $i j$ th bin of the candidate driving cycle and the test data, respectively.

The construction of Xian EV urban driving cycle is shown in Figure 10. The SAPDs of Xi'an EV urban driving cycle and test data are shown in Figures 11 and 12, respectively. A comparison of the Xi'an EV urban driving cycle and test data is shown in Table 9. According to the comparison results, the REs of all assessment parameters are less than $8.81 \%$, the MRE is $4.03 \%$, and the RMSE of the SAPD is $1.32 \%$. The small MRE and RMSE values indicate that the constructed Xian EV urban driving cycle is very close to that based on experimental data from the real-world driving cycle. Therefore, the Xian EV urban driving cycle constructed in this paper can effectively represent the speed-time driving pattern of the real-world cycle in Xian.

\section{Comparison of Driving Cycles}

5.1. Comparison of the Xian and International Standard Driving Cycles. To study the differences between the Xi'an EV urban driving cycle constructed in this paper and the international standard driving cycles, eight characteristic parameters of seven general international standard driving cycles are compared as shown in Figure 13 and Table 10. The seven general international standard driving cycles are the European Economic Commission 15-mode test cycle (ECE 15), New European Driving Cycle (NEDC), Japanese Industrial Standards Committee 08 test cycle (JC08), Japan 10/15 mode test cycle (J10/15), Federal Test Procedures 72 and 75 (FTP72, FTP75), and Worldwide harmonized light duty test cycle (WLTC) [52], respectively. The comparison of results shows that the Xian EV urban driving cycle has greater average acceleration and deceleration values, larger proportions of acceleration and deceleration, and smaller proportions of uniform speed and idling compared to the other driving cycles. Therefore, compared with various general international standard driving cycles, the Xian EV urban driving cycle is characterized by more aggressive driving features.

5.2. Verification of the Construction Method. To verify the advanced and scientific nature of the construction method of the driving cycle proposed in the paper, the driving cycles 
TABLE 9: Comparison of the Xian EV urban driving cycle and test data.

\begin{tabular}{|c|c|c|c|c|c|}
\hline Characteristic parameters & Test data & Driving cycle & $\mathrm{RE}$ & MRE & RMSE \\
\hline Average speed $(\mathrm{km} / \mathrm{h})$ & 20.01 & 20.74 & $3.65 \%$ & \multirow{9}{*}{$4.03 \%$} & \multirow{9}{*}{$1.32 \%$} \\
\hline Maximum speed $(\mathrm{km} / \mathrm{h})$ & 68.22 & 63.86 & $6.39 \%$ & & \\
\hline Average acceleration $\left(\mathrm{m} / \mathrm{s}^{2}\right)$ & 0.76 & 0.78 & $2.63 \%$ & & \\
\hline Average deceleration $\left(\mathrm{m} / \mathrm{s}^{2}\right)$ & 0.78 & 0.77 & $1.28 \%$ & & \\
\hline Standard deviation of acceleration $\left(\mathrm{m} / \mathrm{s}^{2}\right)$ & 0.84 & 0.79 & $5.95 \%$ & & \\
\hline Proportion of acceleration(\%) & 34.5 & 32.9 & $4.64 \%$ & & \\
\hline Proportion of deceleration(\%) & 32.1 & 31.9 & $0.62 \%$ & & \\
\hline Proportion of uniform speed(\%) & 15.9 & 17.3 & $8.81 \%$ & & \\
\hline Proportion of idling(\%) & 17.5 & 17.9 & $2.29 \%$ & & \\
\hline
\end{tabular}

Note: RE is the relative error of the assessment parameters of the candidate driving cycles and the overall test data; MRE is the mean relative error of all assessment parameters; and RMSE is the root mean square error of the SAPD.

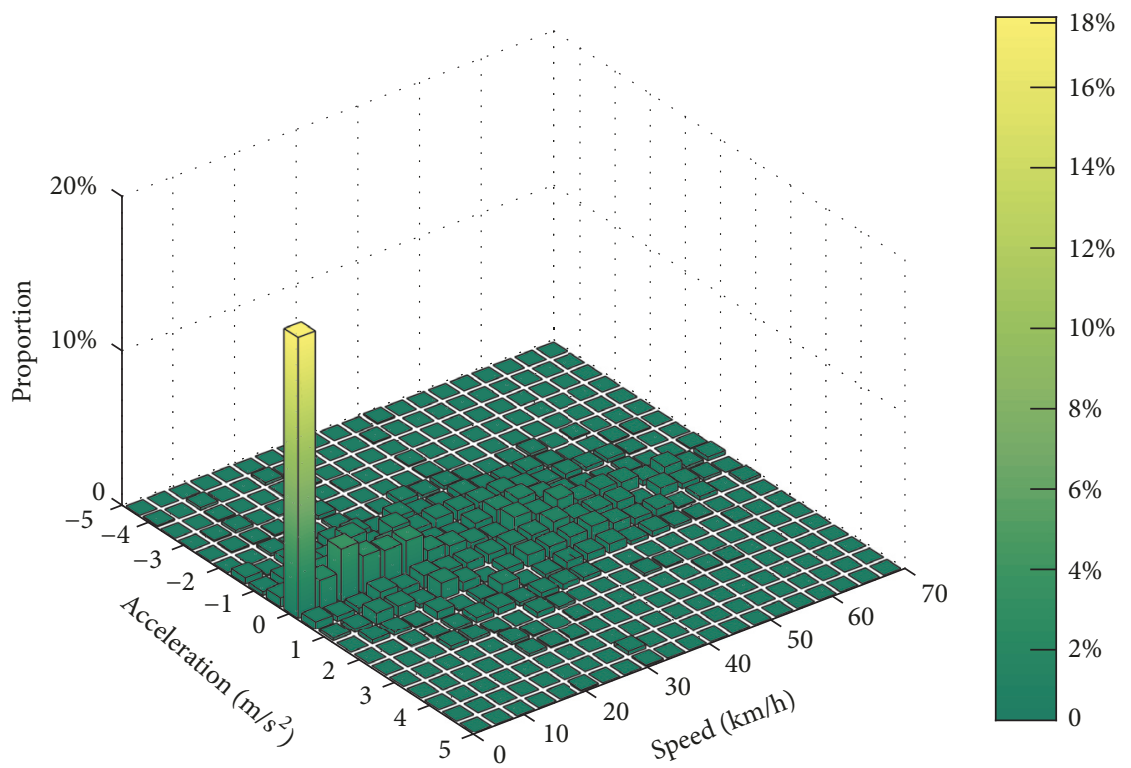

FIgURE 11: SAPD of the Xian EV urban driving cycle.

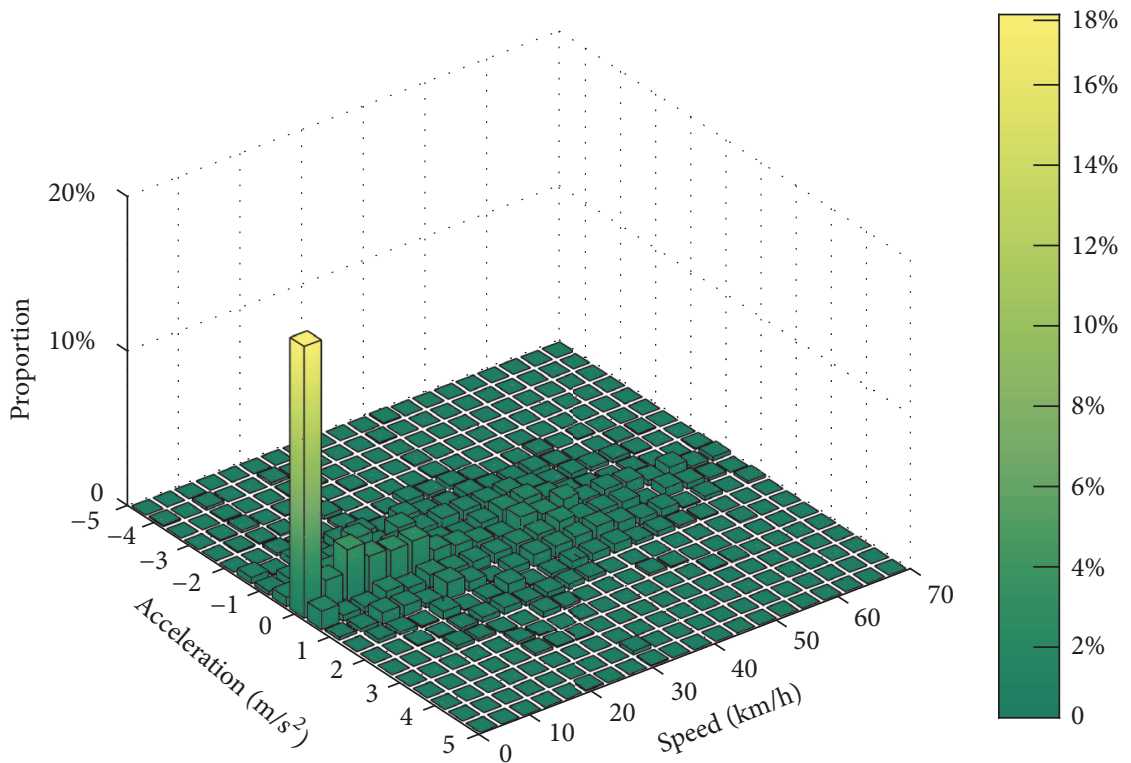

FIGURE 12: SAPD of the test data. 
TABLE 10: Comparison of results for the Xi'an and international standard driving cycles.

\begin{tabular}{|c|c|c|c|c|c|c|c|c|}
\hline Driving cycle & Xian & ECE15 & NEDC & $\mathrm{JC} 08$ & $\mathrm{~J} 10 / 15$ & FTP-72 & FTP-75 & WLTC \\
\hline Vehicle type & $\mathrm{EV}$ & ICEV & ICEV & ICEV & ICEV & ICEV & ICEV & ICEV \\
\hline Road type & Urban & Urban & Composite & Composite & Urban & Urban & Urban & Composite \\
\hline Average speed $(\mathrm{km} / \mathrm{h})$ & 20.74 & 18.4 & 33.6 & 24.4 & 17.7 & 31.5 & 34.1 & 46.5 \\
\hline Maximum speed $(\mathrm{km} / \mathrm{h})$ & 63.86 & 50.0 & 120 & 82.0 & 70.0 & 91.3 & 91.3 & 131.3 \\
\hline Average acceleration $\left(\mathrm{m} / \mathrm{s}^{2}\right)$ & 0.78 & 0.64 & 0.51 & 0.42 & 0.63 & 0.59 & 0.60 & 0.42 \\
\hline Average deceleration $\left(\mathrm{m} / \mathrm{s}^{2}\right)$ & 0.77 & 0.75 & 0.71 & 0.44 & 0.62 & 0.69 & 0.70 & 0.44 \\
\hline Proportion of acceleration(\%) & 32.9 & 21.5 & 23.8 & 27.8 & 25.9 & 32.8 & 32.4 & 29.4 \\
\hline Proportion of deceleration(\%) & 31.9 & 18.5 & 17.6 & 25.9 & 26.4 & 28.3 & 28.2 & 27.8 \\
\hline Proportion of uniform speed(\%) & 17.3 & 29.2 & 34.8 & 17.4 & 22.2 & 20.9 & 21.2 & 30.3 \\
\hline Proportion of idle(\%) & 17.9 & 30.8 & 23.8 & 28.9 & 25.4 & 18.0 & 18.2 & 12.5 \\
\hline
\end{tabular}
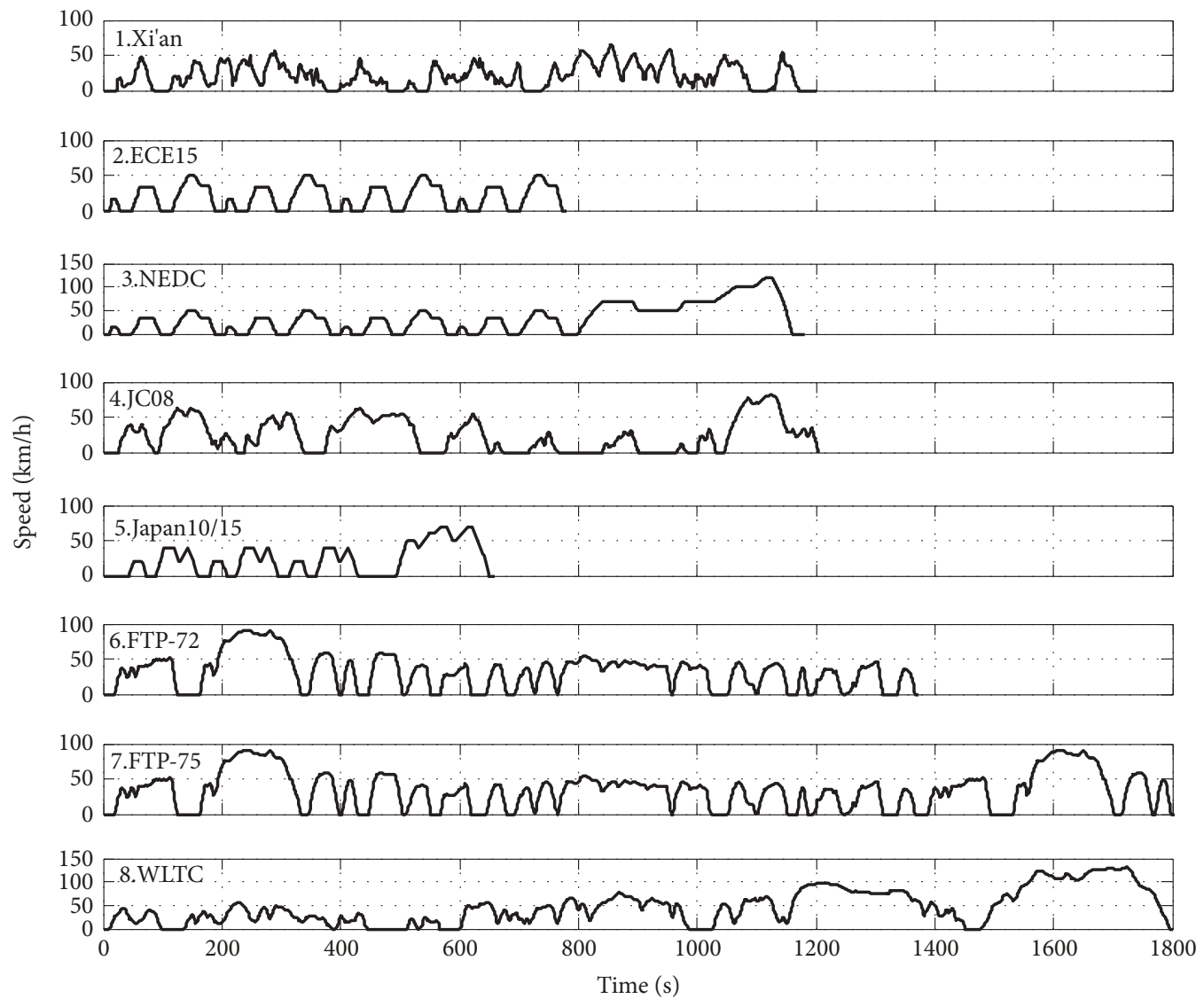

Figure 13: Driving cycles.

constructed by the k-means and SVM hybrid clustering algorithm, k-means clustering algorithm, and fuzzy c-means (FCM) clustering algorithm were compared. The driving cycles constructed by the k-means clustering algorithm and FCM clustering algorithm are shown in Figures 14 and 15, respectively. A comparison of the characteristic parameter results is shown in Table 11. The results indicate that the characteristic parameters of the driving cycle based on the $\mathrm{k}$-means and SVM hybrid clustering algorithm are closest to those of real-world test data. Therefore, the driving cycle constructed in this paper accurately reflects the speed-time and speed-acceleration characteristics of the real-world.

5.3. Comparison of Typical City Driving Cycles. To study the differences between the Xian EV urban driving cycle and other typical city driving cycles, this paper introduces the Winnipeg, Dublin, Mashhad, Hongkong, Ningbo, and Tianjin driving cycles and studies the difference and similarity among driving cycles through comparing the characteristic parameters. A comparison of the results is shown in Table 12. 
TABLE 11: Comparison of the characteristic parameter results.

\begin{tabular}{|c|c|c|c|c|}
\hline Characteristic parameters & Test data & k-means and SVM & k-means & FCM \\
\hline Average speed $(\mathrm{km} / \mathrm{h})$ & 20.01 & 20.74 & 21.59 & 22.47 \\
\hline Maximum speed $(\mathrm{km} / \mathrm{h})$ & 68.22 & 63.86 & 63.07 & 61.42 \\
\hline Average acceleration $\left(\mathrm{m} / \mathrm{s}^{2}\right)$ & 0.76 & 0.78 & 0.69 & 0.74 \\
\hline Average deceleration $\left(\mathrm{m} / \mathrm{s}^{2}\right)$ & 0.78 & 0.77 & 0.76 & 0.79 \\
\hline Standard deviation of acceleration $\left(\mathrm{m} / \mathrm{s}^{2}\right)$ & 0.84 & 0.79 & 0.76 & 0.8 \\
\hline Proportion of acceleration(\%) & 34.5 & 32.9 & 36.0 & 38.33 \\
\hline Proportion of deceleration(\%) & 32.1 & 31.9 & 32.6 & 30.92 \\
\hline Proportion of uniform speed(\%) & 15.9 & 17.3 & 14.3 & 14.01 \\
\hline Proportion of idling(\%) & 17.5 & 17.9 & 17.1 & 16.74 \\
\hline MRE (\%) & - & 4.03 & 6.11 & 6.88 \\
\hline RMSE (\%) & - & 1.32 & 1.89 & 2.04 \\
\hline
\end{tabular}

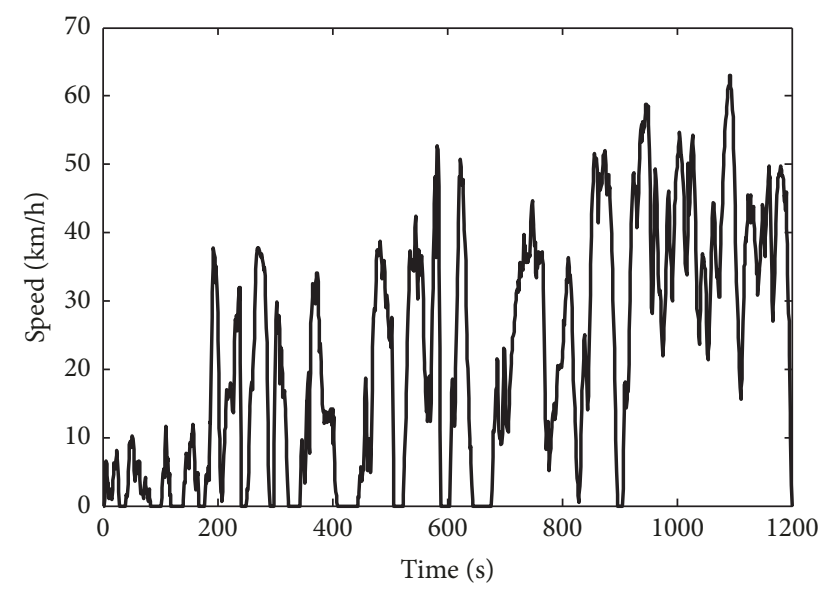

FIGURE 14: Driving cycle based on k-means clustering algorithm.

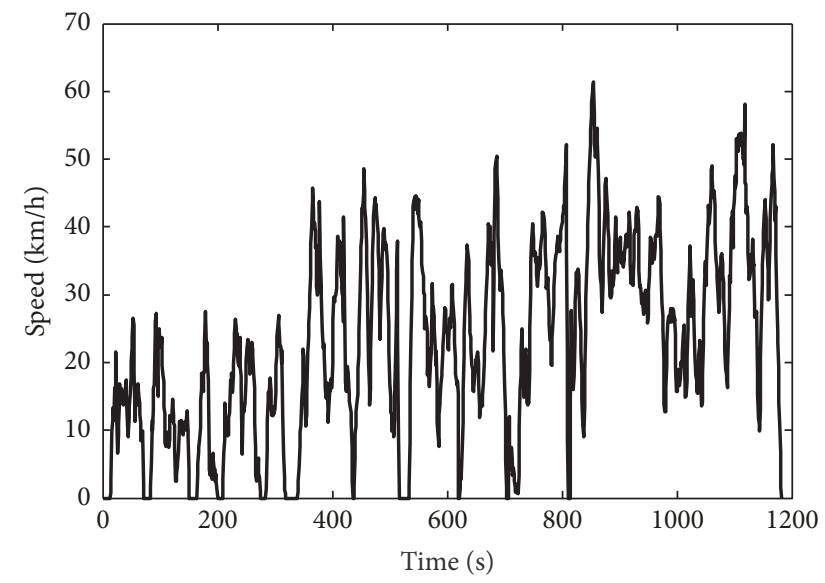

FIGURE 15: Driving cycle based on FCM clustering algorithm.

The average and maximum speeds of the Xi'an EV urban driving cycle are similar to those of the Mashhad and Ningbo driving cycles. Moreover, the average acceleration and average deceleration of Xian EV urban driving cycle are obviously greater than those of other typical city driving cycles, and the proportions of acceleration, deceleration, uniform speed, and idling are similar to those of the Winnipeg driving cycle. Additionally, the average acceleration and average deceleration of the EV driving cycles are obviously greater than those of the ICEV driving cycles, and the EV driving cycles display more aggressive driving characteristics.

According to an analysis of the results, the Xian EV urban driving cycle reflects a more aggressive driving pattern than other driving cycles. The reasons for this finding are threefold. First, car ownership and the urban population have increased rapidly in Xi'an. The city size and transportation infrastructure construction cannot keep up with the increase in car ownership, and urban traffic congestion is serious. Second, the urban driving cycle in this paper is based on EVs, but general international standard driving cycles are based on traditional ICEVs. The start-up acceleration of EVs is obviously higher than that of ICEVs due to the lowspeed constant torque characteristics of the motor [53, 54]. In addition, because the motor provides a fast response and good robustness, slight changes in the accelerator pedal will cause significant speed changes, which is not satisfied by the engine. Therefore, the average acceleration of the EV driving cycle is greater than that of the ICEV driving cycles. Third, to increase the energy utilization rate and driving range of EVs, the motor regenerative braking system can convert kinetic energy into electric energy and recharge batteries during the braking process. Specifically, when the driver releases the accelerator pedal, the EV enters into the regenerative braking mode. However, the ICEV remains in a uniform speed gliding state; therefore, EV experiences greater deceleration.

\section{Conclusions}

This paper proposes a scientific and systematic methodology for the development of a representative EV urban driving cycle. The methodology mainly includes three tasks: test route selection and data collection, data processing, and driving cycle construction. For test route selection and data collection, the overall topological structure of urban roads and traffic flow monitoring results are used as the main factors for the selection of test routes. We combine the advantages of the on-board measurement and chase car methods to collect driving pattern data. In the data processing stage, the 
TABLE 12: Comparison of the results for typical city driving cycles.

\begin{tabular}{|c|c|c|c|c|c|c|c|}
\hline Driving cycle & Xi'an & Winnipeg & Dublin & Mashhad & Hongkong & Ningbo & Tianjin \\
\hline Vehicle type & EV & PHEV & $\mathrm{EV}$ & ICEV & ICEV & ICEV & ICEV \\
\hline Road type & Urban & Composite & Urban & Urban & Urban & Urban & Urban \\
\hline Size of experiment & $\begin{array}{c}56 \text { trips, } 428 \\
\text { hours, } 2158 \mathrm{~km}\end{array}$ & $\begin{array}{l}76 \text { volunteers, } \\
\text { one year }\end{array}$ & 1485 journals & $450 \mathrm{~km}$ & 29 hours & 24 hours & 25 hours \\
\hline Average speed $(\mathrm{km} / \mathrm{h})$ & 20.74 & 31.4 & 30.87 & 20.27 & 25.0 & 23.7 & 22.5 \\
\hline Maximum speed $(\mathrm{km} / \mathrm{h})$ & 63.86 & 100 & 84.5 & 60.90 & 77.7 & 60.2 & 70.2 \\
\hline Average acceleration $\left(\mathrm{m} / \mathrm{s}^{2}\right)$ & 0.78 & 0.60 & 0.62 & 0.53 & 0.60 & 0.51 & 0.36 \\
\hline Average deceleration $\left(\mathrm{m} / \mathrm{s}^{2}\right)$ & 0.77 & 0.60 & 0.64 & 0.54 & 0.60 & 0.58 & 0.43 \\
\hline $\begin{array}{l}\text { Proportion of } \\
\text { acceleration(\%) }\end{array}$ & 32.9 & 31.4 & 26.7 & 37.67 & 34.5 & 37.0 & 36.0 \\
\hline $\begin{array}{l}\text { Proportion of } \\
\text { deceleration(\%) }\end{array}$ & 31.9 & 31.2 & 25.0 & 37.48 & 34.2 & 33.0 & 30.0 \\
\hline $\begin{array}{l}\text { Proportion of uniform } \\
\operatorname{speed}(\%)\end{array}$ & 17.3 & 14.9 & 27.6 & 3.16 & 12.0 & 11.0 & 21.0 \\
\hline Proportion of idle(\%) & 17.9 & 21.8 & 20.7 & 21.70 & 17.8 & 20.0 & 12.0 \\
\hline Reference & - & [29] & {$[3]$} & {$[30]$} & [17] & [32] & [32] \\
\hline
\end{tabular}

PCA algorithm is used to reduce the dimensionality of the characteristic parameters. The driving segments are classified using a k-means and SVM hybrid clustering algorithm, and the classification results of the hybrid method are obviously superior to those of the k-means method. In the driving cycle construction stage, scientific assessment criteria are studied to select the most representative driving cycle from multiple candidate driving cycles. In addition, the SAPDs of the representative Xi'an EV urban driving cycle and realworld test data are compared, and the results show that the Xi'an EV urban driving cycle constructed in this paper effectively represents the speed-time driving pattern of the real-world cycle. Finally, the characteristic parameters of the Xi'an EV urban driving cycle, international standard driving cycles, and other typical city driving cycles are compared and analyzed. The results indicate that the Xian EV urban driving cycle reflects a more aggressive driving characteristic than other driving cycles, mainly due to the difference in the start-up acceleration and regenerative braking characteristics of EVs and ICEVs. Therefore, a representative EV driving cycle should be used for energy optimization, state of charge estimation, and driving mileage prediction for EVs, as well as the evaluation and certification of new EV models.

\section{Data Availability}

The [xls] data used to support the findings of this study are included within the supplementary information file(s). The file named "Test Data. xls" contains part of the data collected during the road test. The file named "Driving Cycle. xls" is Xi'an electric vehicle urban driving cycle constructed in this paper.

\section{Conflicts of Interest}

The authors declare that they have no conflicts of interest.

\section{Acknowledgments}

This research is funded by the National Key R\&D Program of China (2017YFC0803904), National Natural Science Foundation of China (51507013), China Postdoctoral Science Foundation (2018T111006, 2017M613034), Postdoctoral Science Foundation of Shaanxi Province (2017BSHEDZZ36), Shaanxi Province Industrial Innovation Chain Project (2018ZDCXLGY-05-03-01), Shaanxi Provincial Key Research and Development Plan Project (2018ZDXM-GY-082), and Shaanxi Innovative Talents Promotion Plan Project (2018KJXX-005).

\section{Supplementary Materials}

The "Test Data" file records some of the speed-time data collection during the test. The "Driving Cycle" file records the speed-time data of driving cycle based on k-means and SVM proposed in this paper. (Supplementary Materials)

\section{References}

[1] S. Zhang, R. Xiong, and C. Zhang, "Pontryagin's Minimum Principle-based power management of a dual-motor-driven electric bus," Applied Energy, vol. 159, pp. 370-380, 2015.

[2] S. Zhang and R. Xiong, "Adaptive energy management of a plugin hybrid electric vehicle based on driving pattern recognition and dynamic programming," Applied Energy, vol. 155, pp. 6878, 2015.

[3] J. Brady and M. O'Mahony, "Development of a driving cycle to evaluate the energy economy of electric vehicles in urban areas," Applied Energy, vol. 177, pp. 165-178, 2016.

[4] W. N. Lourido, L. E. Munoz, and J. E. Pereda, "A methodology to obtain a synthetic driving cycle through GPS data for energy analysis," in Proceedings of the 12th IEEE Vehicle Power and Propulsion Conference, VPPC 2015, Canada, October 2015.

[5] S. Xie, H. He, and J. Peng, "An energy management strategy based on stochastic model predictive control for plug-in hybrid electric buses," Applied Energy, vol. 196, pp. 279-288, 2017. 
[6] Z. Chen, B. Xia, C. You, and C. C. Mi, "A novel energy management method for series plug-in hybrid electric vehicles," Applied Energy, vol. 145, pp. 172-179, 2015.

[7] L. Dang, N. Bernard, N. Bracikowski, and G. Berthiau, "Design optimization with flux weakening of high-speed PMSM for electrical vehicle considering the driving cycle," IEEE Transactions on Industrial Electronics, vol. 64, no. 12, pp. 9834-9843, 2017.

[8] Z. Chen, R. Xiong, K. Wang, and B. Jiao, "Optimal energy management strategy of a plug-in hybrid electric vehicle based on a particle swarm optimization algorithm," Energies, vol. 8, no. 5, pp. 3661-3678, 2015.

[9] Y. Wang, H. Fujimoto, and S. Hara, "Driving force distribution and control for EV with four in-wheel motors: a case study of acceleration on split-friction surfaces," IEEE Transactions on Industrial Electronics, vol. 64, no. 4, pp. 3380-3388, 2017.

[10] B. Gasbaoui and A. Nasri, "A novel 4WD electric vehicle control strategy based on direct torque control space vector modulation technique," Intelligent Control Automation, vol. 3, no. 03, pp. 236-242, 2012.

[11] K. Hartani, M. Bourahla, Y. Miloud, and M. Sekour, "Electronic differential with direct torque fuzzy control for vehicle propulsion system," Turkish Journal of Electrical Engineering \& Computer Sciences, vol. 17, no. 1, pp. 21-38, 2014.

[12] S. A. Oleksowicz, K. J. Burnham, A. Southgate et al., "Regenerative braking strategies, vehicle safety and stability control systems: critical use-case proposals," Vehicle System Dynamics, vol. 51, no. 5, pp. 684-699, 2013.

[13] J. Nadeau, M. Boisvert, and P. Micheau, "Implementation of a cooperative strategy between a vehicle's mechanical and regenerative brake system," in Proceedings of the 2014 IEEE Vehicle Power and Propulsion Conference, VPPC 2014, Portugal, October 2014.

[14] Z. Zhang, L. Wang, J. Zhang, and R. Ma, "Study on requirements for load emulation of the vehicle with an electric braking system," IEEE Transactions on Vehicular Technology, vol. 66, no. 11, pp. 9638-9653, 2017.

[15] C. Hou, M. Ouyang, L. Xu, and H. Wang, "Approximate Pontryagin's minimum principle applied to the energy management of plug-in hybrid electric vehicles," Applied Energy, vol. 115, pp. 174-189, 2014.

[16] M. Helmbrecht, C. Olaverri-Monreal, K. Bengler, R. Vilimek, and A. Keinath, "How electric vehicles affect driving behavioral patterns," IEEE Intelligent Transportation Systems Magazine, vol. 6, no. 3, pp. 22-32, 2014.

[17] W. T. Hung, H. Y. Tong, C. P. Lee, K. Ha, and L. Y. Pao, “Development of a practical driving cycle construction methodology: A case study in Hong Kong," Transportation Research Part D: Transport and Environment, vol. 12, no. 2, pp. 115-128, 2007.

[18] S. Shi, N. Lin, Y. Zhang et al., "Research on Markov property analysis of driving cycles and its application," Transportation Research Part D: Transport and Environment, vol. 47, pp. 171181, 2016.

[19] A. Fotouhi and M. Montazeri-Gh, "Tehran driving cycle development using the k-means clustering method," Scientia Iranica, vol. 20, no. 2, pp. 286-293, 2013.

[20] S. H. Kamble, T. V. Mathew, and G. K. Sharma, "Development of real-world driving cycle: case study of Pune, India," Transportation Research Part D: Transport and Environment, vol. 14, no. 2, pp. 132-140, 2009.
[21] M. Knez, T. Muneer, B. Jereb, and K. Cullinane, “The estimation of a driving cycle for Celje and a comparison to other European cities," Sustainable Cities and Society, vol. 11, pp. 56-60, 2014.

[22] M. Fellah, G. Singh, A. Rousseau, S. Pagerit, E. Nam, and G. Hoffman, "Impact of real-world drive cycles on PHEV battery requirements," SAE Technical Papers, 2009.

[23] E. Tate, M. O. Harpster, and P. J. Savagian, "The electrification of the automobile: from conventional hybrid, to plug-in hybrids, to extended-range electric vehicles," Sae International Journal of Passenger Cars Electronic \& Electrical Systems, vol. 1, no. 1, pp. 156-166, 2009.

[24] L. Berzi, M. Delogu, and M. Pierini, "Development of driving cycles for electric vehicles in the context of the city of Florence," Transportation Research Part D: Transport and Environment, vol. 47, pp. 299-322, 2016.

[25] G. Wager, J. Whale, and T. Braunl, "Driving electric vehicles at highway speeds: The effect of higher driving speeds on energy consumption and driving range for electric vehicles in Australia," Renewable \& Sustainable Energy Reviews, vol. 63, pp. 158-165, 2016.

[26] H. He, J. Guo, N. Zhou, C. Sun, and J. Peng, "Freeway driving cycle construction based on real-time traffic information and global optimal energy management for plug-in hybrid electric vehicles," Energies, vol. 10, no. 11, 2017.

[27] A. Esteves-Booth, T. Muneer, H. Kirby, J. Kubie, and J. Hunter, "The measurement of vehicular driving cycle within the city of Edinburgh," Transportation Research Part D: Transport and Environment, vol. 6, no. 3, pp. 209-220, 2001.

[28] R. Günther, T. Wenzel, M. Wegner, and R. Rettig, "Big data driven dynamic driving cycle development for busses in urban public transportation," Transportation Research Part D Transport \& Environment, vol. 51, pp. 276-289, 2017, http://dx.doi.org/10.1016/j.trd.2017.01.009.

[29] R. Smith, S. Shahidinejad, D. Blair, and E. L. Bibeau, "Characterization of urban commuter driving profiles to optimize battery size in light-duty plug-in electric vehicles," Transportation Research Part D: Transport and Environment, vol. 16, no. 3, pp. 218-224, 2011.

[30] M. A. Pouresmaeili, I. Aghayan, and S. A. Taghizadeh, "Development of Mashhad driving cycle for passenger car to model vehicle exhaust emissions calibrated using on-board measurements," Sustainable Cities and Society, vol. 36, pp. 12-20, 2018.

[31] Q. Wang, H. Huo, K. He, Z. Yao, and Q. Zhang, "Characterization of vehicle driving patterns and development of driving cycles in Chinese cities," Transportation Research Part D: Transport and Environment, vol. 13, no. 5, pp. 289-297, 2008.

[32] H. Achour and A. G. Olabi, "Driving cycle developments and their impacts on energy consumption of transportation," in Proceedings of the International Conference on Sustainable Energy \& Environmental Protection, vol. 112, pp. 1778-1788, 2012.

[33] U. Galgamuwa, L. Perera, and S. Bandara, "Development of a driving cycle for Colombo, Sri Lanka: an economical approach for developing countries," Journal of Advanced Transportation, vol. 50, no. 7, pp. 1520-1530, 2016.

[34] Z. Yu, S. Shi, S. Wang et al., "Statistical inference-based research on sampling time of vehicle driving cycle experiments," Transportation Research Part D: Transport and Environment, vol. 54, pp. 114-141, 2017.

[35] H. Y. Tong and W. T. Hung, "A framework for developing driving cycles with on-road driving data," Transport Reviews, vol. 30, no. 5, pp. 589-615, 2010. 
[36] N. H. Arun, S. Mahesh, G. Ramadurai, and S. M. S. Nagendra, "Development of driving cycles for passenger cars and motorcycles in Chennai, India," Sustainable Cities and Society, vol. 32, pp. 508-512, 2017.

[37] S.-H. Ho, Y.-D. Wong, and V. W.-C. Chang, "Developing Singapore Driving Cycle for passenger cars to estimate fuel consumption and vehicular emissions," Atmospheric Environment, vol. 97, pp. 353-362, 2014.

[38] J. I. Huertas, J. Díaz, D. Cordero, and K. Cedillo, "A new methodology to determine typical driving cycles for the design of vehicles power trains," International Journal on Interactive Design and Manufacturing, vol. 12, no. 1, pp. 319-326, 2018.

[39] J. D. K. Bishop, C. J. Axon, and M. D. McCulloch, "A robust, data-driven methodology for real-world driving cycle development," Transportation Research Part D: Transport and Environment, vol. 17, no. 5, pp. 389-397, 2012.

[40] P. Seers, G. Nachin, and M. Glaus, "Development of two driving cycles for utility vehicles," Transportation Research Part D: Transport and Environment, vol. 41, pp. 377-385, 2015.

[41] K. Pearson, "Principal components analysis," The London, Edinburgh, and Dublin Philosophical Magazine and Journal of Science, vol. 6, no. 2, p. 559, 1901.

[42] Y. Hua, H. Jiang, H. Tian, X. Xu, and L. Chen, "A comparative study of clustering analysis method for driver's steering intention classification and identification under different typical conditions," Applied Sciences, vol. 7, no. 10, p. 1014, 2017.

[43] P. Yuhui, Z. Yuan, and Y. Huibao, "Development of a representative driving cycle for urban buses based on the K-means cluster method," Cluster Computing, pp. 1-10, 2018.

[44] W. M. Rand, "Objective criteria for the evaluation of clustering methods," Journal of the American Statistical Association, vol. 66, no. 336, pp. 846-850, 1971.

[45] G. S. Davidson, B. N. Wylie, and K. W. Boyack, "Cluster stability and the use of noise in interpretation of clustering," in Proceedings of the IEEE Symposium on Information Visualization 2001 (INFOVIS), pp. 23-30, USA, October 2001.

[46] S. Ben-David and U. Von Luxburg, "Relating clustering stability to properties of cluster boundaries," in Proceedings of the 21st Annual Conference on Learning Theory, COLT 2008, pp. 379390, Finland, July 2008.

[47] U. Von Luxburg, "Clustering stability: An overview," Foundations and Trends in Machine Learning, vol. 2, no. 3, pp. 129-168, 2009.

[48] S. Ben-David, D. Pál, and H. U. Simon, "Stability of k-means clustering," in Proceedings of the Conference on Learning Theory, vol. 4539, pp. 20-34, 2007.

[49] C. Cortes and V. Vapnik, "Support-vector networks," Machine Learning, vol. 20, no. 3, pp. 273-297, 1995.

[50] V. N. Vapnik, The Nature of Statistical Learning Theory, Springer, 1995.

[51] A. Rakhlin and A. Caponnetto, "Stability of K-means clustering," in Proceedings of the 20th Annual Conference on Neural Information Processing Systems, NIPS 2006, pp. 1121-1128, Canada, December 2006.

[52] M. Tutuianu, P. Bonnel, B. Ciuffo et al., "Development of the World-wide harmonized Light duty Test Cycle (WLTC) and a possible pathway for its introduction in the European legislation," Transportation Research Part D: Transport and Environment, vol. 40, pp. 61-75, 2015.

[53] X. Zhao, Q. Yu, M. Yu, and Z. Tang, "Research on an equal power allocation electronic differential system for electric vehicle with dual-wheeled-motor front drive based on a wavelet controller," Advances in Mechanical Engineering, vol. 10, no. 2, 2018.

[54] X. Zhao, S. Xu, Y. Ye, M. Yu, and G. Wang, "Composite braking AMT shift strategy for extended-range heavy commercial electric vehicle based on LHMM/ANFIS braking intention identification," Cluster Computing, pp. 1-16, 2018. 


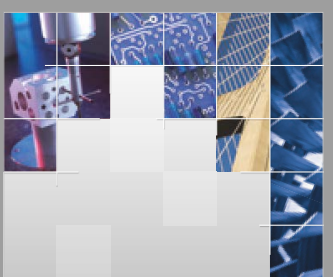

\section{Enfincering}
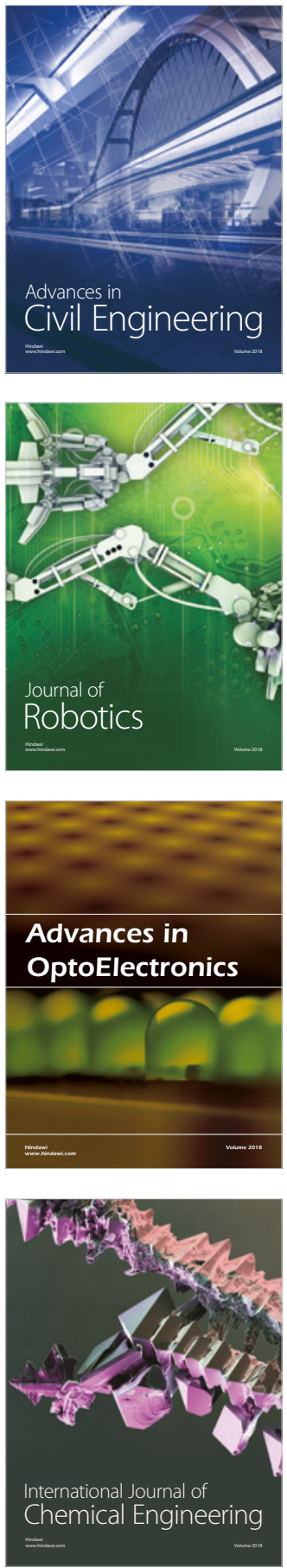

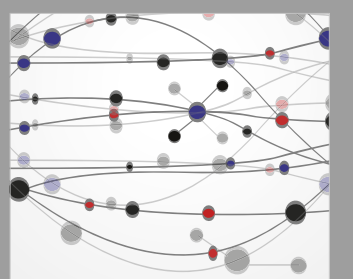

\section{Rotating \\ Machinery}

The Scientific World Journal

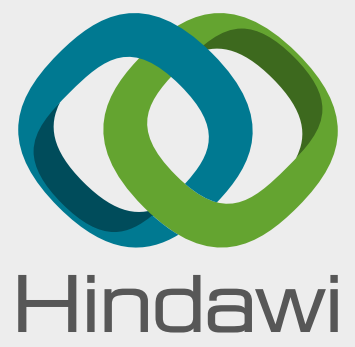

Submit your manuscripts at

www.hindawi.com
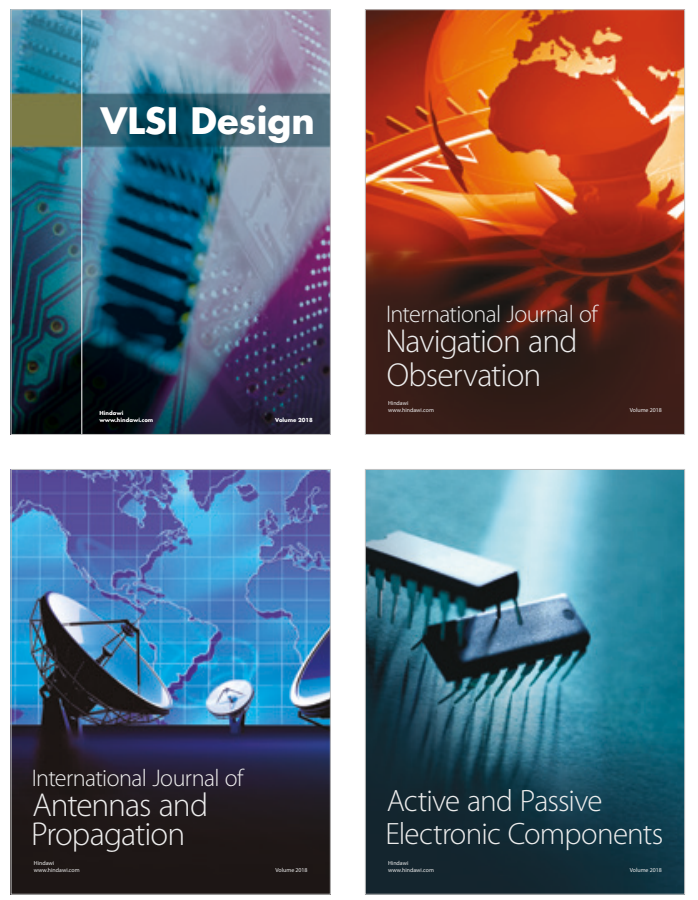
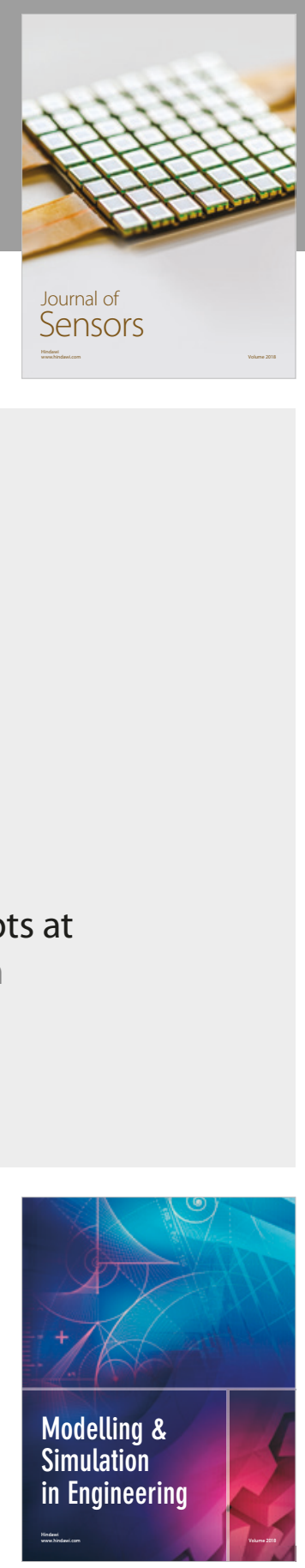

\section{Advances \\ Multimedia}
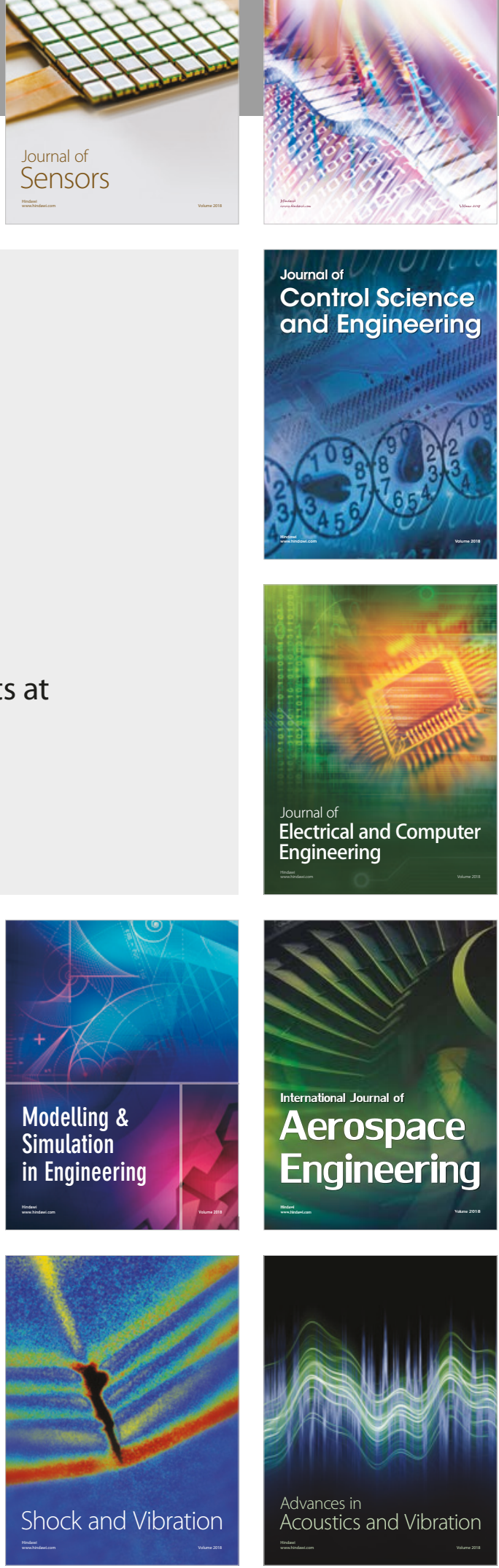